\title{
Understanding the Effects of Wind Intensity, Forward Speed, Pressure and Track on Generation and Propagation of Hurricane Irma Surges around Florida
}

\author{
Abram Musinguzi ${ }^{1}$, Madinah Shamsu ${ }^{1}$, Muhammad K. Akbar ${ }^{1}{ }^{*}$ and Jason G. Fleming ${ }^{2}$ \\ 1 Department of Mechanical and Manufacturing Engineering, Tennessee State University, \\ Nashville, TN 37209, USA; amusingu@tnstate.edu (A.M.); mshamsu@tnstate.edu (M.S.) \\ 2 Seahorse Coastal Consulting, 3103 Mandy Ln, Morehead City, NC 28557, USA; \\ jason.fleming@seahorsecoastal.com \\ * Correspondence: makbar@tnstate.edu; Tel.: +1-615-963-5392
}

check for updates

Citation: Musinguzi, A.; Shamsu, M.; Akbar, M.K.; Fleming, J.G.

Understanding the Effects of Wind Intensity, Forward Speed, Pressure and Track on Generation and Propagation of Hurricane Irma Surges around Florida. J. Mar. Sci. Eng. 2021, 9, 963. https://doi.org/ 10.3390/jmse9090963

Academic Editors: Eugen Rusu and Christos Stefanakos

Received: 27 July 2021

Accepted: 1 September 2021

Published: 4 September 2021

Publisher's Note: MDPI stays neutral with regard to jurisdictional claims in published maps and institutional affiliations.

Copyright: (c) 2021 by the authors. Licensee MDPI, Basel, Switzerland. This article is an open access article distributed under the terms and conditions of the Creative Commons Attribution (CC BY) license (https:/ / creativecommons.org/licenses/by/ $4.0 /)$.

\begin{abstract}
In this study, it is demonstrated that hurricane wind intensity, forward speed, pressure, and track play an important role on the generation and propagation of coastal storm surges. Hurricane Irma, which heavily impacted the entire Florida peninsula in 2017 , is used to study the storm surge sensitivity to varying storm characteristics. Results show that the west coast experiences a negative surge due to offshore wind of the approaching storm, but the positive surge returns after the hurricane eye passes over a location and wind became onshore. In the west coast peak, surges are intensified by an increase in onshore wind intensity and forward speed. In the Florida Keys, peak surges are intensified by an increase in wind intensity, a decrease in forward speed and a decrease in pressure. In southeast and east Florida, peak surges are intensified by decrease in pressure, although overall surges are less significant as the water can slide along the coastline. In the recessed coastline of Georgia-Carolinas, maximum surge is elevated by an increase in onshore wind intensity. Shifting the track westward increases peak surges on the west coast, while shifting the track eastward increases peak surge on the east coast. The results demonstrate a new understanding about the sensitivity of surge to varying parametric conditions and the importance of considering changes in the coastline orientation in storm surge predictions.
\end{abstract}

Keywords: storm surge; wind intensity; forward speed; surface pressure; track; hurricane Irma

\section{Introduction}

A storm surge, an abnormal rise of water generated by a storm, over and above the predicted astronomical tide, depends on several factors including storm intensity, size, surface pressure, forward speed, track and angle of approach, landfall location and bathymetry [1]. As a storm proceeds out of the tropics, both hurricane forward speed and the hurricane track angle relative to the coast strongly influence the propagation of the wind directions. Other important factors that are expected to influence coastal storm surges include the attributes of the coastal landscape such local geographical features, and the shape of the coastline [1-3].

Lessons from several different recent hurricanes indicate that surge-induced inundation in coastal zones cannot be solely estimated from the Saffir-Simpson hurricane scale [4] that relies on the maximum storm wind speed as the only determining factor. For many decades, both research and operational forecasting have heavily relied on the Saffir-Simpson scale to determine peak surges. The National Hurricane Center's (NHC) determining factor in the scale is solely based on the maximum sustained wind speed, defined as maximum 1-min wind at the standard meteorological observation height of $10 \mathrm{~m}$ [5]. While the above scale has been widely used as a management tool for alerting the public about the possible impacts of hurricane damage based on wind speed, it offers 
a limited consideration of other important parameters such as forward speed, track, and storm size, which often lead to serious over or under prediction of surges, and to a false public perception of safety. For example, Hurricane Katrina (2005), a category 3 storm and Hurricane Sandy (2012), a category 1 storm, produced a much higher storm surge than Hurricane Irma (2017), a category 5 storm.

A numerical experiment was conducted on Hurricane Rita (2005) to investigate the impact of wind intensity, forward speed, radius of maximum winds, tidal timing, amplitude, and wind inflow angle on inundation over a wide and shallow shelf. It was concluded that varying a storm's forward motion may account for variations in flooded volumes equivalent to an upgrade or downgrade of about 1 category on the Saffir-Simpson scale [6]. Flooding due to variations in forward speed is associated with the duration over which the storm impacts the coastal zones. Slower storms cause lower peak surges that push more water far inland and inundate large sections of the coast, while faster storms increase peak surges on the shoreline but inundate narrower sections of the coast [6-8]. For instance, a $25 \%$ decrease in forward speed caused a $0.25-0.5 \mathrm{~m}$ increase in peak surges in bays, lakes, and rivers, while a $25 \%$ increase in forward speed increased the nearshore peak surges by 0.25-0.5 m during Hurricane Rita [7]. Thomas et al. [8] demonstrated that, for Hurricane Matthew (2016), a long shore-parallel storm, faster storm increased peak water levels along the coast, but a slower storm pushed more water into the estuaries and bays.

When hurricane winds and steering winds travel in the same direction, the forward speed adds to the strength of the winds on the right side of the storm [9]. The increased winds on the right side due to the additive effect of the forward speed increases the storm surge. A pioneer study [7] investigated the combined effect of wind speed and forward speed on the storm surge impacts of Hurricane Rita in Louisiana and the Texas coast on the Gulf of Mexico, by simultaneously decreasing or increasing wind speed and forward speed. The study observed a $1.5 \mathrm{~m}$ increase in storm surge when both parameters were increased by $25 \%$, but the opposite happened when both parameters were decreased by $25 \%$. The combined effect of wind speed and forward speed was more evident on the east side of land fall where counterclockwise winds are stronger. However, the study observed that simultaneously increasing wind intensity and decreasing forward speed has the greatest effect on storm surge, since the hurricane has the strength and time to push the surge inland.

Sebastian et al. [10] numerically examined the effect of track and wind speed of Hurricane Ike (2008) along the Texas coast. The study explored the effect of the track with various landfall locations both east and west of the original landfall. They determined that shifting the storm westward causes higher levels of surge due to more intense, higher shore-normal winds. The study further observed that increasing wind speeds by $15 \%$ results in an approximately $23 \%$ increase in surge. Irish et al. [11] used idealized hurricanes to perform a sensitivity analysis of storm surge to hurricane storm size (radius of winds), track, and forward speed for different bottom slopes. Their results showed that for a given shelf slope, the peak surge increases by up to $30 \%$ as the storm size increases, indicating that storm size effectively increases the distance over which the wind acts.

The nature and slope of the continental shelf plays a critical role to the magnitude of hurricane storm surges. For example, the effects of surge-induced inundation tend to be greater when winds act on a wide and gentle sloping continental shelf [12]. In contrast, hurricane-driven storm surges and waves adjacent to deep ocean islands, are highly influenced by the pressure deficit of the hurricanes [13]. A study examined the impact of Hurricane Irma on the Florida peninsula and found that storm surges on the west coast of Florida were distinctly different from those on the east coast [14]. The study determined that barometric pressure had a limited effect on storm surge along the west coast. On both east and west coasts, onshore winds brought a positive surge. Offshore winds, which happened on the west coast, brought negative surges. Shore perpendicular winds had a larger impact on surges than shore parallel winds. 
The goal of the current study is to understand the impact of wind intensity, forward speed, pressure, and track on the generation and propagation of Hurricane Irma storm surges, focusing around the Florida peninsula, which has not been done in previous studies. First, the effects of individual parameters are explored, and then the combined effects of wind intensity, forward speed, pressure and track are studied by simultaneously increasing or decreasing each of parameter. The results demonstrate the sensitivity of Irma's surge-induced inundation in different regions around Florida to storm parameters and track. The current investigation is a part of a series of studies using different hurricanes aimed to understand the generation and propagation of hurricane storm surges. At the end of the series, a comprehensive article is expected to be published summarizing the pseudo-generalized understanding of the topic.

The remainder of the paper proceeds as follows. An overview of Irma's synoptic history and its impacts is provided in Section 2. The methodology for numerical experimentation is presented in Section 3. Section 4 presents results, and Section 5 summarizes study findings.

\section{Irma Synoptic History}

The synoptic history described in this paper is based on the National Hurricane Center's Hurricane Irma report [15]. Hurricane Irma took place between 1 September 2017 to 13 September 2017. It originated from a tropical wave that departed the west coast of Africa on 27 August 2017. By 0000 UTC 30 August 2017, it developed into a tropical depression, and after cyclogenesis, the depression became a tropical storm $6 \mathrm{~h}$ later. It rapidly intensified and by 5 September 2017 Irma had attained category 5 status, reaching its maximum intensity of $178 \mathrm{mph}$ when it was located about 80 mile east-southeast of Barbuda.

After making its first land fall in Barbuda, Irma maintained category 5 status and caused widespread devastation as it passed through Barbuda, the British Virgin Islands, north of Puerto Rico and the Dominican Republic. Irma ended its $60 \mathrm{~h}$ period of sustained category 5 intensity, which is the second longest such period on record behind the 1932 Cuba Hurricane of Santa Cruz del Sur. Thereafter, it weakened to a category 4 status while moving through the southern Bahamas, but regained category 5 status as it turned westwards toward Cuba after only $18 \mathrm{~h}$. Irma made its fifth landfall near Cayo Romano, Cuba, at 0300 UTC on 9 September 2017.

As Irma tracked along the Cuban Keys, its interaction with land caused significant structural changes and weakening, first to a category 4 storm a few hours after landfall in the Cuban Keys and then down to a category 2 hurricane. This was followed by a subsequent slowdown in the forward speed, and a track change to the northwest, which caused the core of the hurricane to move over the Florida Straits by 10 September 2017.

As it moved over the warm waters in the Florida Straits, the hurricane intensified again to category 4 status, making its first of two U.S. landfalls near Cudjoe Key, Florida, at 1300 UTC on 10 September 2017. The category 4 storm made its second and final U.S. landfall in southwest Florida near Marco Island, at 1930 UTC on 10 September 2017.

Once inland over southwestern Florida, Irma weakened quickly, due to the influences of land and strong wind shear, and by 0000 UTC on 11 September 2017 it downgraded to a category 2 hurricane, and then to a category 1 storm 6 h later. Irma continued to weaken, falling to a tropical storm by 1200 UTC on 11 September 2017 as it moved across northern Florida, most of the deep convection being located well to the northeast of the center, and the strongest winds were confined to the northeast coast of Florida and southeastern Georgia [15]. It weakened into a remnant low by 0600 UTC 12 September 2017. The remnant low continued northwestward while weakening, and dissipated shortly after 1200 UTC 13 September 2017. 


\section{Methodology}

\subsection{Mesh and Hydrodynamic Model}

This study uses the Hurricane Surge On-Demand Forecasting System (HSOFS) mesh [16], which is prepared to be used in an Advanced Circulation (ADCIRC) model for operational surge and tide predictions for the US East Coast and Gulf of Mexico. The mesh covers the US coast from Maine through Texas and it has 3,564,104 and 1,813,443 nodes and elements, respectively. The mesh has an average resolution of $500 \mathrm{~m}$ along the coast, with some areas decreasing to a resolution of $150 \mathrm{~m}$. The HSOFS is a reasonably acceptable mesh for the storm surge study around the Florida peninsula, as shown in Figure 1a.

The ADCIRC and Simulating Waves Nearshore (ADCIRC + SWAN) is a tightly coupled model used to simulate waves and storms. ADCIRC uses the continuous-Galerkin finite element method to solve shallow-water equations to model hurricane storm surges on unstructured meshes $[17,18]$. The wind drag formulation of Powell, with a cap of 0.0028 , is adopted in this study, as was done in previous studies [3,19]. A spatially varying Manning's $n$ bottom friction is based on the Coastal Change Analysis Program (CCAP) regional land cover data. The SWAN model is a third-generation wave model [20], which is tightly coupled with ADCIRC to produce random, short-crested wind-generated waves on top of storm surges. SWAN uses the same HSOFS mesh as ADCIRC for the meteorological, bottom friction, water level and current. The ADCIRC Manning's $n$ values are converted to roughness lengths and used in SWAN. The Komen formulation is used for white capping; dissipation by death-induced breaking and bottom friction are activated; and three wave-wave interactions (triads) are activated [20]. The numerical propagation scheme is first order backward space backward time. The timestep for SWAN is set to $600 \mathrm{~s}$ for all simulations. The spectral space is discretized using 36 directional bins witha directional resolution of $10^{\circ}$ and 30 frequency bins with a logarithmic resolution over the range 0.03 to $0.55 \mathrm{~Hz}$. Note that ADCIRC + SWAN is used in the study simply to incorporate the contribution of waves in the storm surges. Studying the wave characteristics is not currently a part of the investigation.

\subsection{Meteorological Forcing}

ADCIRC requires the specification of a meteorological input file with wind velocity and atmospheric pressure fields. Configuration of parameters of wind intensity fields are modified by increasing or decreasing the multiplier in the meteorological input file. The surface pressure can be increased or decreased by applying a variable pressure multiplier in the ADCIRC source code, as was described in [7]. The time increment of the meteorological forcing is specified through a meteorological wind time interval. This parameter can be controlled in the model parameter and a periodic boundary condition file to vary the forward speed of the storm. Details of these files can be found in ADCIRC documentation [21].

The Interactive Objective Kinematic Analysis (IOKA) by Ocean weather Inc. (OWI), a data-assimilated wind model for the meteorological forcing, is used in the present study. In this model, wind and surface pressure fields are generated based on observations from anemometers, airborne and land-based Doppler radar, microwave radiometers, buoys, ships, aircraft, coastal stations, and satellite measurements [22,23]. Studies [3,19] found OWI wind and pressure fields to be the best for hurricane Rita hindcast based on error statistics and correlation coefficient. Similarly, the OWI is found to be a reasonably good representation of the atmospheric forcing for Hurricane Matthew and matched well with the observed time series of surface pressures and wind speeds [8]. Therefore, the OWI wind field is considered as the reference meteorological forcing for Hurricane Irma in the present study. 


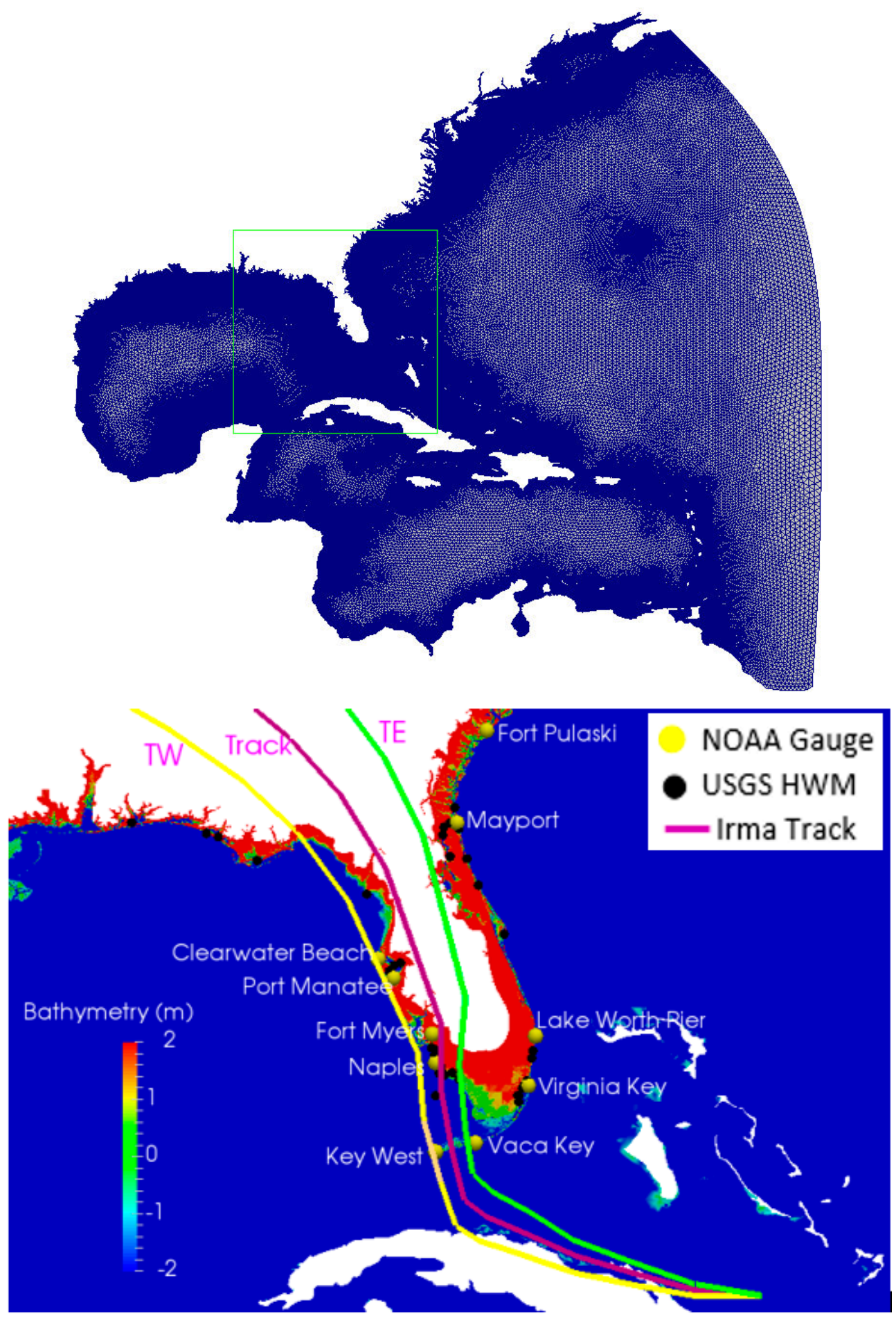

(b)

Figure 1. Computational mesh, tracks and observation stations, (a) HSOFS mesh and focus area (green box), (b) Focus area and observation station locations with respect to hurricane Irma track and two hypothetical tracks. The original track (Track) and hypothetical tracks TE and TW shifted $5^{\circ}$ east and west of original track, respectively.

Different cases are simulated in which four major hurricane parameters are varied: (1) wind intensity, (2) forward speed, (3) surface pressure, and (4) track. Table 1 shows the summary of the experimental cases simulated. Case 1 is the reference simulation in which the original values (i.e., $100 \%$ wind intensity, $100 \%$ forward speed, $100 \%$ pressure, actual track) of OWI wind field data are maintained. In Cases 2 through 9, individual parameters 
are changed one at a time. Since Irma was already a powerful storm, only a $10 \%$ wind intensity increment is considered. Forward speed is increased and decreased by $25 \%$ and $10 \%$, respectively. The minimum surface pressure is varied at increments of $3.3 \%$, although the local surface pressure multiplier depends on the distance from the hurricane eye. The pressure change is performed using a rectangular hyperbola distribution, as described in [7]. To examine the influence of the path and track of Irma, the track along the south Florida coast is shifted, to explore two landfall scenarios both east and west of the original landfall (Figure 1b). Two hypothetical tracks, TE and TW, are created by manually shifting the track $5^{\circ}$ east and west with respect to the original track. The shift originates from the hurricane eye location about $48 \mathrm{~h}$ before the Florida landfall time of 1800 UTC on 10 September 2017. The original Irma track has the landfall in the southwest of Florida, as shown in Figure 1b. The TE track goes over the center of the Florida peninsula and the TW track goes along the west coast of Florida. These $5^{\circ}$ shifted tracks are chosen to provide two good variations of the original track.

Table 1. Parametric combinations used for different cases.

\begin{tabular}{ccccc}
\hline \multirow{2}{*}{ Case } & \multicolumn{4}{c}{ Parameters } \\
\cline { 2 - 5 } & Wind Intensity & Forward Speed & Pressure & Track \\
\hline 1 & $100 \%$ & $100 \%$ & $100 \%$ & $100 \%$ \\
\hline 2 & $110 \%$ & $100 \%$ & $100 \%$ & $100 \%$ \\
\hline 3 & $90 \%$ & $100 \%$ & $100 \%$ & $100 \%$ \\
\hline 5 & $100 \%$ & $90 \%$ & $100 \%$ & $100 \%$ \\
\hline 6 & $100 \%$ & $125 \%$ & $100 \%$ & $100 \%$ \\
\hline 7 & $100 \%$ & $100 \%$ & $96.7 \%$ & $100 \%$ \\
\hline 8 & $100 \%$ & $100 \%$ & $103.3 \%$ & $100 \%$ \\
\hline 9 & $100 \%$ & $100 \%$ & $100 \%$ & $5^{\circ}$ West \\
\hline 10 & $100 \%$ & $100 \%$ & $100 \%$ & $5{ }^{\circ}$ East \\
\hline 11 & $90 \%$ & $90 \%$ & $100 \%$ & $100 \%$ \\
\hline 12 & $110 \%$ & $125 \%$ & $100 \%$ & $100 \%$ \\
\hline 13 & $90 \%$ & $125 \%$ & $100 \%$ & $100 \%$ \\
\hline 14 & $110 \%$ & $90 \%$ & $100 \%$ & $100 \%$ \\
\hline 15 & $100 \%$ & $90 \%$ & $96.7 \%$ & $100 \%$ \\
\hline & $110 \%$ & $90 \%$ & $96.7 \%$ & $100 \%$ \\
\hline
\end{tabular}

In Cases 10 through 15, wind intensity, forward speed and pressure are simultaneously changed to examine their combined effects on the hindcasted surge. Note that some other combinations were run, but only the most impactful cases are presented here for brevity. Each simulation is cold-started from 0000 UTC 16 July 2017, with a 50.5-day tides-only period that allows the tides to reach a dynamic equilibrium. A hot-start file is created from this run. This is followed by a 7.5-day Irma simulation from 1200 UTC 04 September 2017 to 0000 UTC 12 September 2017. Although ADCIRC is hot-started from the tide only run file created previously, the SWAN run is cold-started with the wave field set to zero at 1200 UTC 04 September 2017 [24].

\subsection{Model Validation}

The agreement between the modeled and observed water levels is quantified using three statistical performance indicators: Coefficient of Determination $\left(R^{2}\right)$; Mean Normalized Bias $\left(B_{M N}\right)$; and Root Mean Square Error $\left(E_{R M S}\right)$. Coefficient of Determination $\left(R^{2}\right)$ describes how well a regression line fits a set of data and has an ideal value of one. Mean 
Normalized Bias $\left(B_{M N}\right)$ indicates the model's magnitude of overprediction or underprediction, normalized to the observed value, with an ideal value of zero, and is expressed as

$$
B_{M N}=\frac{\frac{1}{N} \sum_{i=1}^{N} E_{i}}{\frac{1}{N} \sum_{i}^{N}\left|O_{i}\right|}
$$

Root Mean Square Error $\left(E_{R M S}\right)$ is an indication of the magnitude of error, with an ideal value of zero; and can be expressed as

$$
E_{R M S}=\frac{1}{N} \sum_{i=1}^{N} E_{i}^{2}
$$

where $O$ is the observed value, $E$ is the error in terms of simulated minus observed and $N$ is the number of datapoints.

In previous studies, such as [2,7], the above statistics were used to validate the model performance by utilizing only the wet stations or points, which is called the wet-only method. In this method, error statistics are computed only at locations wetted by ADCIRC + SWAN. A total of 47 HWM points are distributed along the South Florida coast, as shown in Figure 1b.

\section{Results}

\subsection{Evolution of Maximum Winds and Water Levels}

In Figure 2, the contour plots of Cases 2, 1 and 3 show the effect of increasing wind intensity on maximum wind velocity magnitude and maximum water elevation of storm surges that happen at every mesh node over the entire duration of the hurricane. For brevity, the rest of the cases are not shown in this figure, since the wind intensity remains the same for all as that of Case 2. The increase in wind intensity increases the effect of maximum winds, which is observed by the relative distance of contour lines $20 \mathrm{~m} / \mathrm{s}$ (or $30 \mathrm{~m} / \mathrm{s}$ ) from the hurricane track in Figure 2a,c, and e. In a previous study [7], authors found that the storm size was inadvertently increased due to a linear increase of the wind intensity multiplier. This finding holds true in this study as well. The maximum water elevation increases with the wind intensity due to a stronger overland push in the southwest end of the Florida peninsula and in the recess of the Georgia-Carolinas coastline, as a comparative study of Figure $2 b, d$, and $f$ shows. Similar findings for Rita hindcast studies were reported by Rego et al. [6] and Irish et al [11], who observed that the effect of varying wind intensity on a storm surge is similar in magnitude to that of varying the radius of maximum wind along the coast of Louisiana. As reported in [14,15], the east coast experienced a positive surge due to onshore wind perpendicular to the shoreline, whereas the west coast mostly experienced a negative surge (Figure 2 does not show it) due to offshore winds. The positive surge returned on the west coast after the hurricane eye passed a location and onshore wind pushed the water towards the coast. On the southeast coast of Florida, water was able to slide up north, which minimized the surge height, if any. In the recess of the Georgia-Carolinas coastline there was a funnel effect, which helped water accumulation, leading to a high surge, although the location is a bit away from the storm path. 


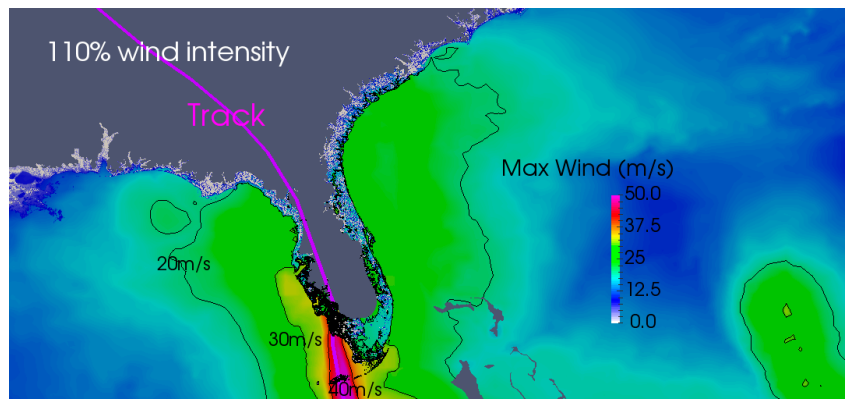

(a)

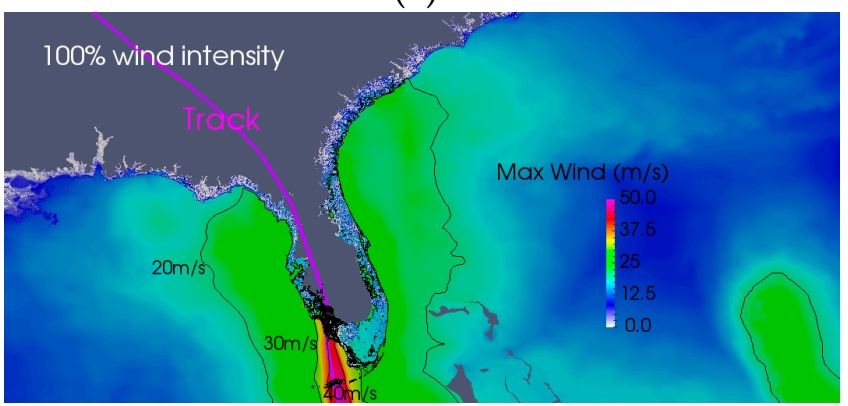

(c)

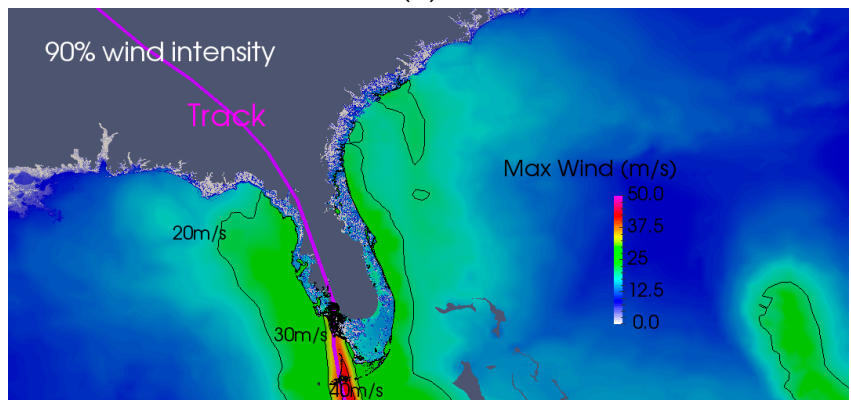

(e)

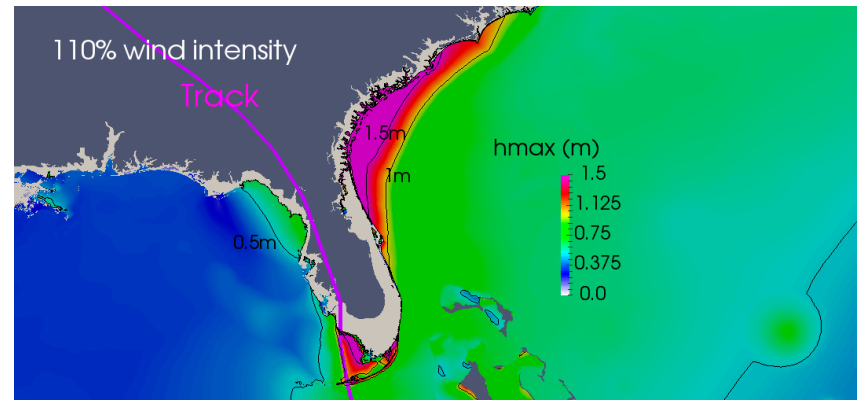

(b)

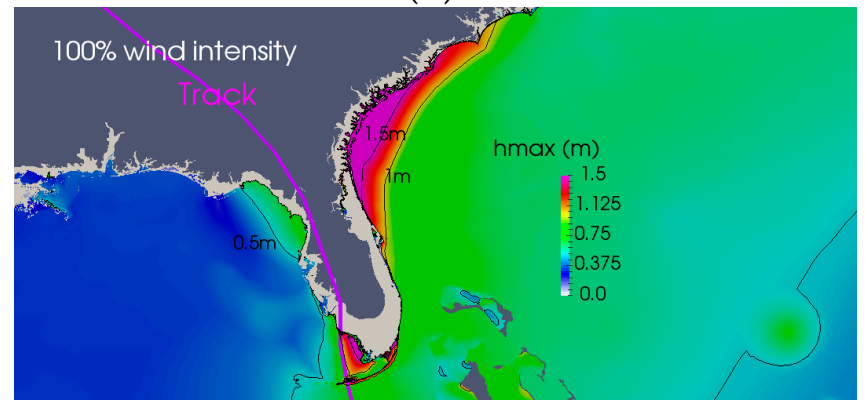

(d)

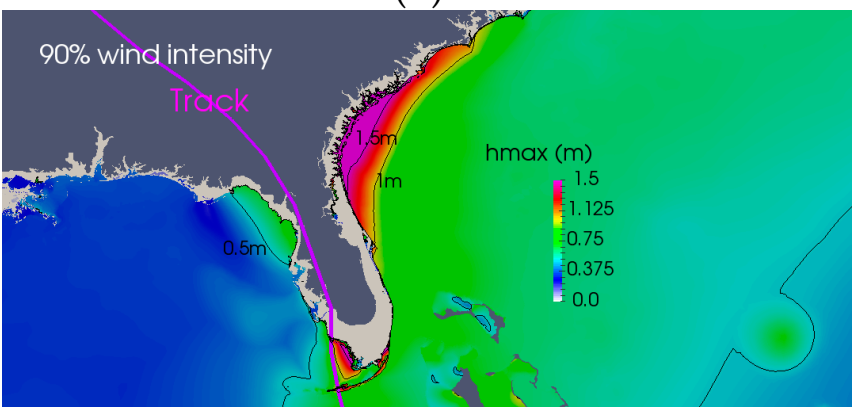

(f)

Figure 2. Effect of wind intensity on the maximum wind velocity magnitude and maximum water elevation; (a,b) Case 2, $(\mathbf{c}, \mathbf{d})$ Case 1, and (e,f) Case 3. Left column: maximum wind velocity magnitude; right column: maximum water elevations. Relevant contour lines are displayed in each figure.

The wind intensity and its impact on storm surge is further demonstrated by snapshots of wind velocity vectors and velocity magnitude color plots at the landfall times, as shown in Figure 3 for Cases 2 and 3. Hurricane Irma made a landfall in Florida Keys at 1300UTC on 10 September 2017 near Cudjoe Key, then a final landfall near Marco Island in southwest Florida, at 1930 UTC on 10 September 2017. Asymmetric and anticlockwise rotating wind with stronger right-side patterns are observed at both landfalls in Figure 3. However, it can be noticed that the wind is stronger during the landfall in Florida Keys (Figure 3a,b) than in the southwest coast (Figure 3c,d). It can be clearly seen from a comparison between Figure 3 column 1 and column 2 that increasing the wind intensity increases the storm size, indicating that wind intensity affects the area over which the storm acts. On the east coast, the wind remained onshore that caused positive surges. On the west coast, initially, the wind was offshore that caused negative surges. However, after the hurricane passed over the location, the wind returned onshore, which lead to positive surges. In the recess of the Georgia-Carolinas coastline, the onshore wind was mostly shore perpendicular, which caused high surges. 


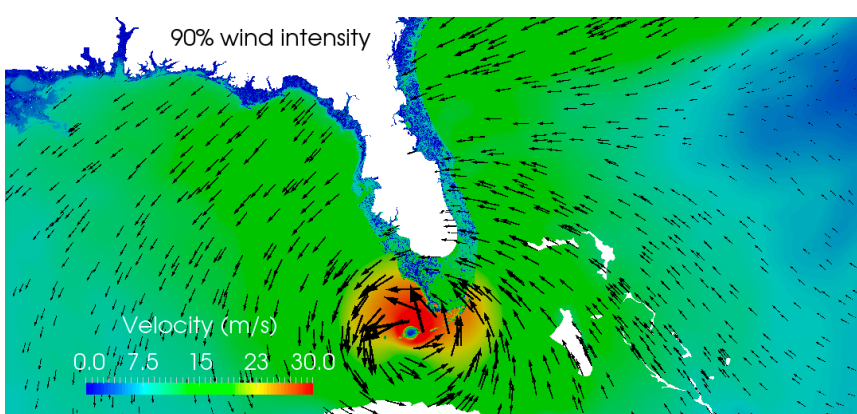

(a)

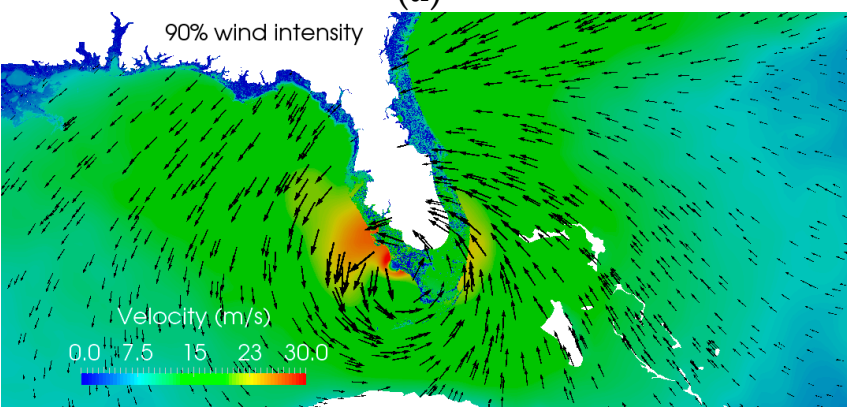

(c)

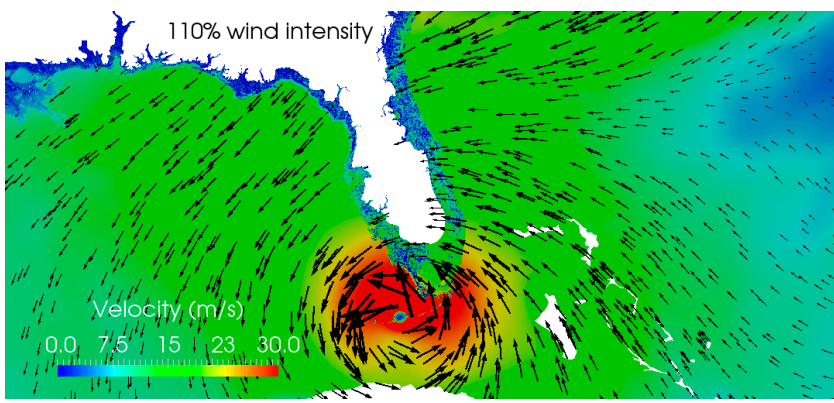

(b)

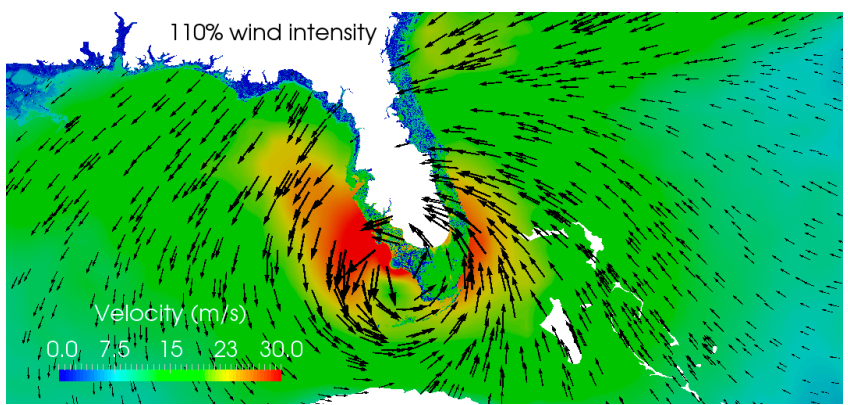

(d)

Figure 3. Snapshots of wind vector and velocity magnitude color plots at landfall. (a) Case 3 at 1:00 p.m., 10 September 2017; (b) Case 2 at 1:00 p.m., 10 September 2017; (c) Case 3 8:00 p.m., 10 September 2017; and (d) Case 2 at 8:00 p.m., 10 September 2017.

To ascertain the actual quantitative effects of individual parameters shown in Cases 2-9 (see Table 2), the maximum water elevation differences between the reference case (Case 1) and each other case (i.e., Case 1-Case 2, etc.) were computed. Figure 4a,b indicate the effect of varying wind intensity on Irma peak surges. When the wind intensity is increased by $10 \%$, about $0.2 \mathrm{~m}$ increase in peak surges occurred around the landfall areas of Cudjoe Key and the Naples area. This increase in surge is due to stronger onshore winds pushing water overland after the hurricane eye passed over these locations. Observation reports indicated that all of the greater Naples area received hurricane force-sustained winds, with category 2 sustained winds likely affecting much of the southern and eastern portions of Naples. A similar increase in surge is observed in the east Florida coast and on the concave shaped coastline of Georgia-Carolinas. The contrary happens when the wind intensity is decreased by $10 \%$.

Table 2. National Oceanic and Atmospheric Administration (NOAA) observation stations used in the study.

\begin{tabular}{|c|c|c|c|c|c|}
\hline NOAA ID & Name & Longitude & Latitude & Bathymetry (m) & Location \\
\hline 8670870 & Fort Pulaski & -80.9017 & 32.0333 & -5.284 & East coast \\
\hline 8720218 & Mayport & -81.4300 & 30.3967 & -8.313 & East coast \\
\hline 8722670 & Lake Worth Pier & -80.0333 & 26.6117 & -6.437 & East coast \\
\hline 8723214 & Virginia Key & -80.1618 & 25.7314 & -3.686 & East coast \\
\hline 8724580 & Key West & -81.8079 & 24.5557 & -1.388 & Florida Keys \\
\hline 8723970 & Vaca Key & -81.1133 & 24.7117 & -1.512 & Florida Keys \\
\hline 8725110 & Naples & -81.8075 & 26.1317 & -0.323 & West coast \\
\hline 8725520 & Fort Myers & -81.8717 & 26.6483 & -2.067 & West coast \\
\hline 8726384 & Port Manatee & -82.5633 & 27.6383 & 0.235 & West coast \\
\hline 8726724 & Clearwater & -82.8317 & 27.9783 & -1.888 & West coast \\
\hline
\end{tabular}




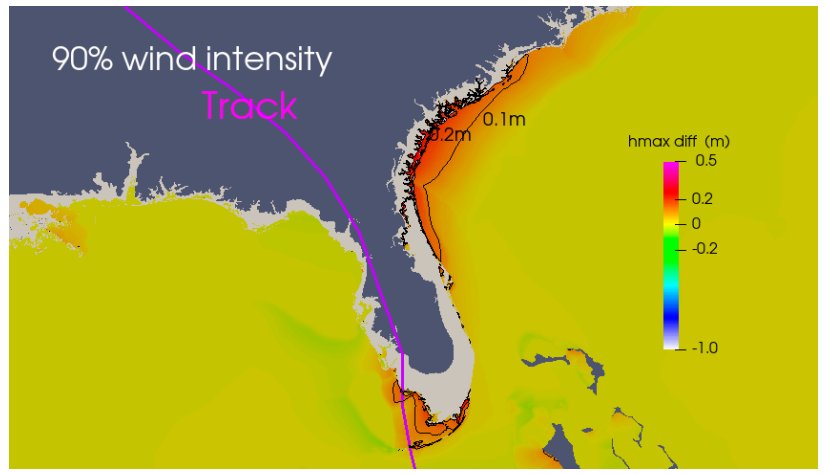

(a)

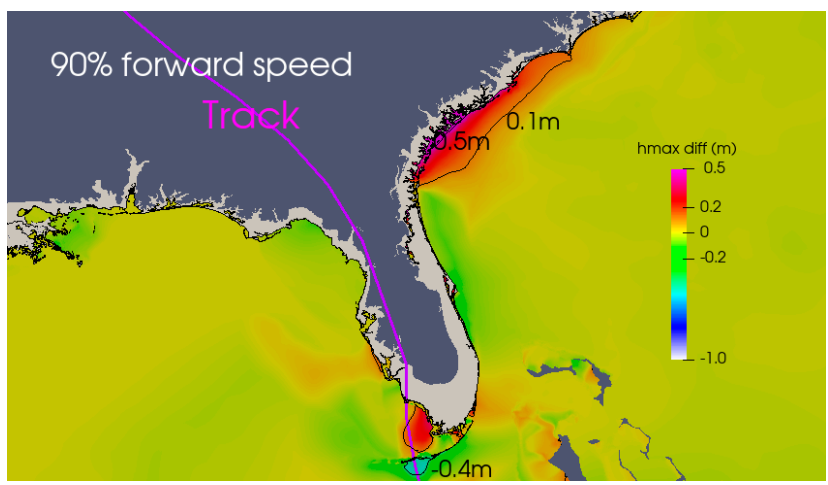

(c)

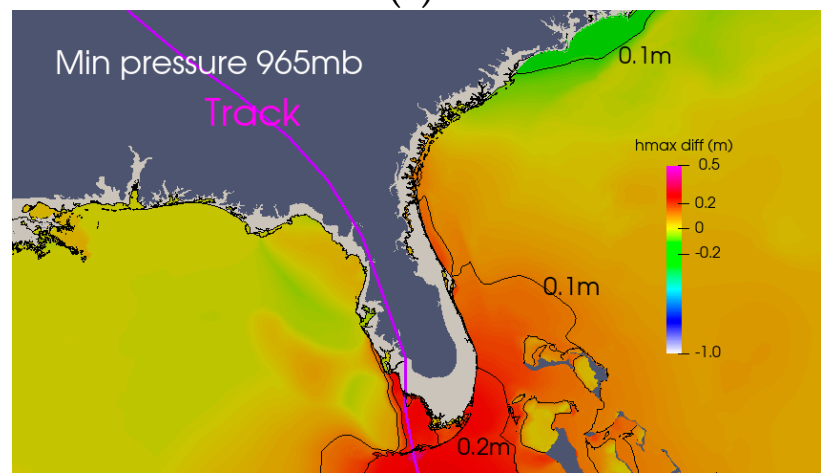

(e)

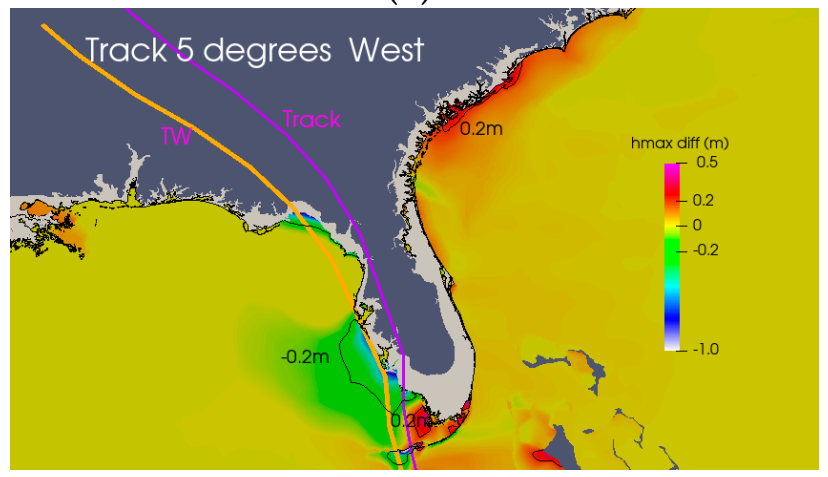

(g)

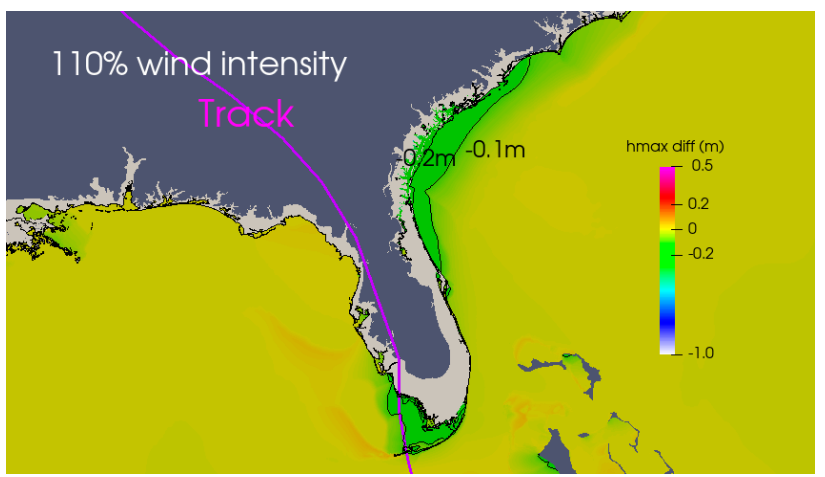

(b)

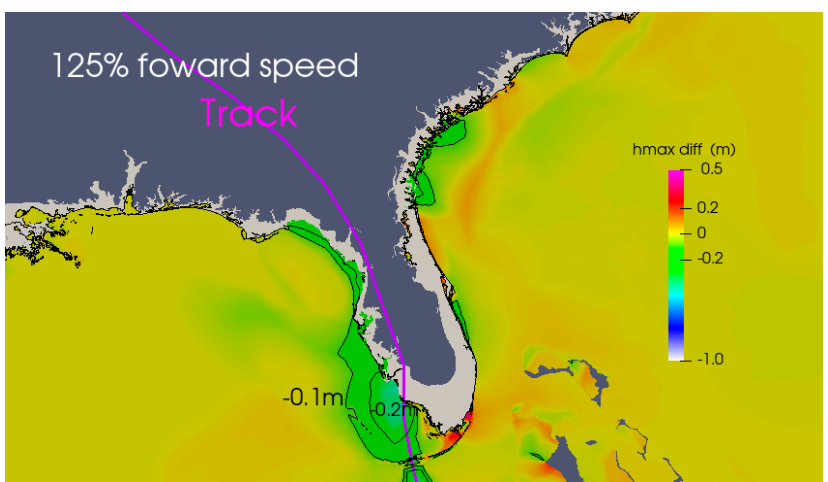

(d)

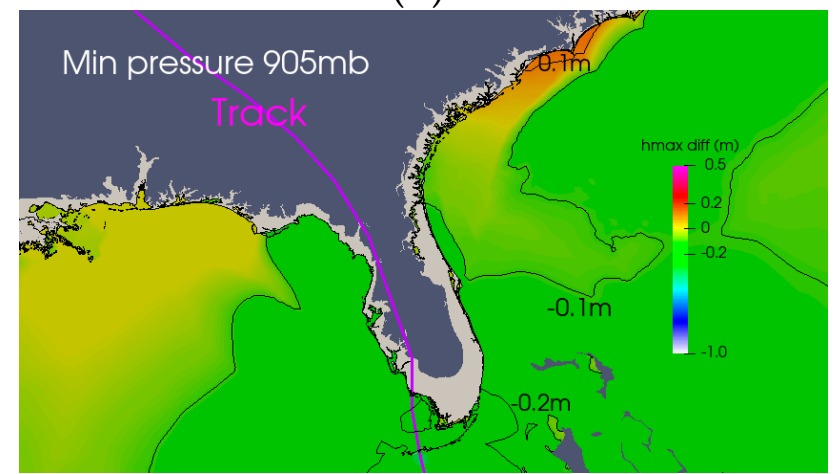

(f)

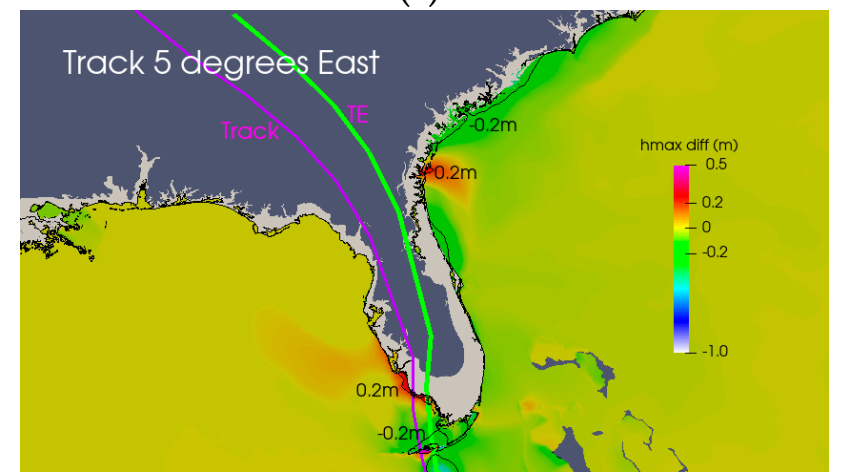

(h)

Figure 4. Departure of maximum water elevations from the base case (i.e., "hmax" of each simulation is subtracted from that of the reference simulation); (a) Case 1-Case 3; (b) Case 1-Case 2; (c) Case 1-Case 4; (d) Case 1-Case 5; (e) Case 1-Case 7; (f) Case 1-Case 6; (g) Case 1-Case 8; and (h) Case 1-Case 9. Purple lines represent the Irma track. 
A reduction in the hurricane forward speed by $10 \%$ increases the peak surges in the south side of Florida Keys by more than $0.4 \mathrm{~m}$, but decreased by the same amount on the north side, as seen in Figure 4c. This is possibly because high onshore winds take more time to push water against the key islands from the south, thereby increasing the peak surges. The peak levels remain low on the open coast, since the forward speed is slow to push water back onshore. There is a decrease of more than $0.5 \mathrm{~m}$ in peak water levels along the Georgia-Carolinas coastline and a decrease in forward speed. The funnel effect subsided as more time was allowed for the water to disperse. On the other hand, when the forward speed is increased (Figure 4d), there is a $0.2 \mathrm{~m}$ increase in flooding in the open coast areas of west and southwestern Florida as the wind has enough momentum to push water against the shoreline. Along the Georgia-Carolinas coastline, the surge is slightly higher as well. A $0.2 \mathrm{~m}$ decrease in peak surge occurs in the southeast Florida, at the intersection of Florida Keys and continental Florida.

As shown in Figure 4e, as the pressure is increased, there is about a $0.2 \mathrm{~m}$ reduction in surge levels on the near shore. On the other hand, as Figure $4 \mathrm{f}$ shows, a decrease in pressure results in about a $0.2 \mathrm{~m}$ surge increase. Both are due to the inverted barometer effect. The effect is along the track and widely spread in the open ocean, especially along the south coast of Florida. Musinguzi et al. [7] observed similar findings during Hurricane Rita. In agreement with this theoretical relationship, [13] found surge levels to rise by 0.8 to $1 \mathrm{~m}$ around Puerto Rico and the U.S. Virgin Islands for Hurricanes Irma and Maria, with center pressures of 914 and 910 millibars, respectively. The surge level increasing or decreasing by $0.2 \mathrm{~m}$ for a 30 millibar incremental pressure drop or rise in the present study is within $67 \%$ of the classical theoretical relationship mentioned above. The results are reasonable, given that the region of the study is a continental shelf with land effects and not a deep ocean.

To examine the influence of the track on peak surges, the original Irma track is shifted $5^{\circ}$ westwards and eastwards, starting from the eye location about $48 \mathrm{~h}$ before the landfall. As shown in Figure 4g, h, lines TW and TE represent the original track shifted $5^{\circ}$ westwards and eastwards, respectively. Figure $4 \mathrm{~g}$ shows that shifting the track $5^{\circ}$ westwards increases the peak surge by more than $0.2 \mathrm{~m}$ on the west coast of Florida. Shifting the track $5^{\circ}$ eastwards increases the peak surge by more than $0.2 \mathrm{~m}$ along the Georgia-Carolinas coastlines, as seen in Figure $4 \mathrm{~h}$. From the comparison of vector snapshots displayed in Figure $5 a, b$, it is clear that the $5^{\circ}$ westward storm pushes wind onshore in the southwest Florida after the hurricane eye passes a location, causing a higher surge there. When the track is shifted $5^{\circ}$ eastwards (Figure $5 \mathrm{c}$ ), a stronger onshore wind is active on the east coast than west, causing a slightly higher surge on the east coast. Note that the track is on the continental Florida for the most part, which minimizes the surge effects overall. As the storm moved up north, on-shore winds pushed more water to inundate most of the Georgia-Carolinas coastline.

\subsection{Water Level Timeseries for Observed and Model Predictions}

As shown in Figure 6, modeled Hurricane Irma water level timeseries are compared to the observed water levels at 10 selected locations in south Florida. The identification number for the National Oceanic and Atmospheric Administration (NOAA) gauge stations and location bathymetric depths are shown in Table 2. Fort Pulaski is located near Savannah River on South Carolina-Georgia border, while Mayport is located on St. Johns River east of Jacksonville, Florida. Lake Worth Pier and Virginia Key stations are located far away to the east of landfall, Key West and Vaca Key are located close to the land fall areas in the Florida Keys. Naples and Fort Myers are located close to the landfall areas near north of Marcos Island, while Port Manatee and Clearwater are located farther north of landfall areas in southwest Florida. The bathymetry and geographic locations of these gauge stations with respect to the track are shown in Figure 1b. 


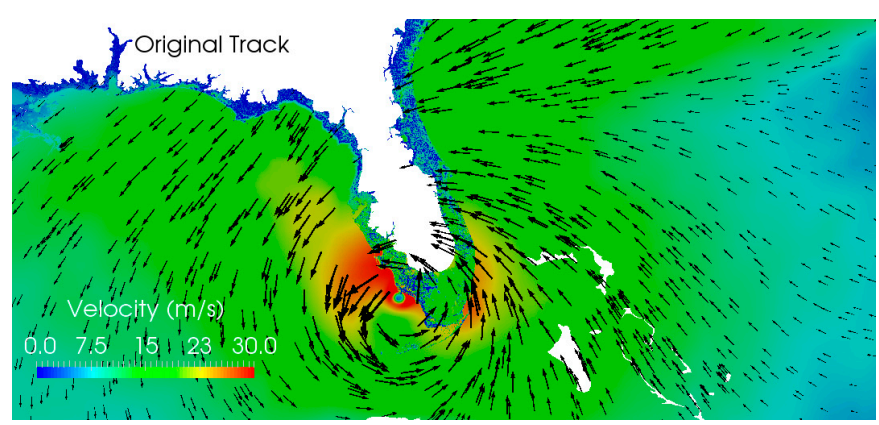

(a)

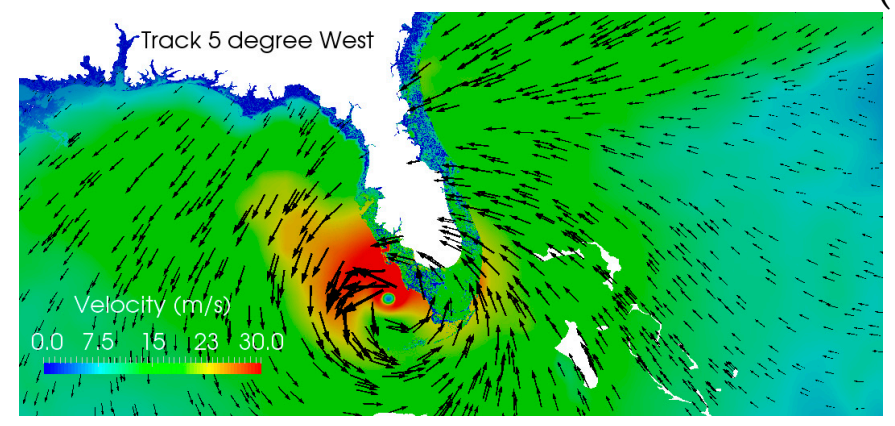

(b)

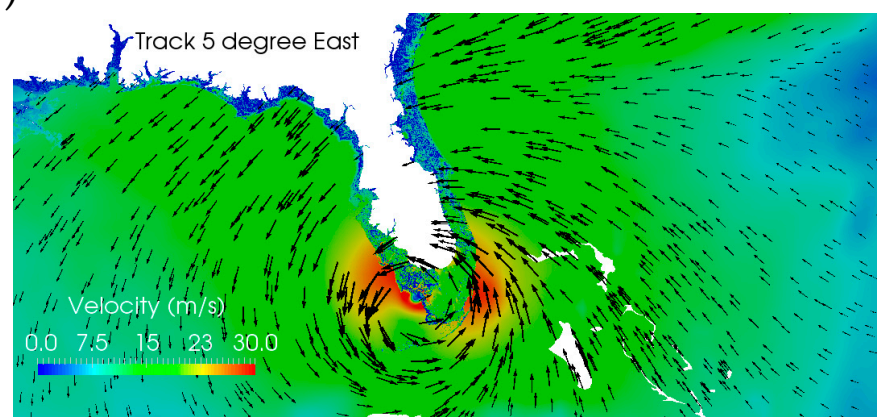

(c)

Figure 5. Snapshots of wind vector and velocity magnitude color plots; (a) Case 1 wind vector at 8:00 p.m., 10 September 2017; (b) Case 8 wind vector at 9:00 p.m., 10 September 2017; (c) Case 9 wind vector at 4:00 a.m., 10 September 2017.

To further understand the effect of the varying parameters (i.e., Cases 2-9) listed in Table 1, modeled water level time series are compared to the modeled water level time series using OWI (i.e., Case 1) meteorological forcing, as well as the observed water levels at eight stations in South Florida. In comparison with the observed data, the OWI model results are acceptable and are well comparable to those presented in a recent study done using the parallel Coastal and Estuarine Storm Tide (CEST) Model [25], indicating that OWI well represented Hurricane Irma windfields. Overall, OWI underpredicts the Irma surge at all stations except at the Virginia Key station. The greatest underprediction of more than $0.9 \mathrm{~m}$ occurs at Fort Myers. Fort Myers station is located deep inside a river channel. The water path from the ocean to the station goes through a tortuous path. Any inaccuracies in the mesh, Manning's n coefficient and bathymetry along the way is bound to cause some discrepancy and delay in surge peaks. In the Key West station, the model underpredicts by about $0.5 \mathrm{~m}$, and the reason for this underprediction is possibly a coarser mesh resolution in the Key West region. However, as shown in Figure 6, water level time series with varying parameters in OWI indicate overprediction by some models and underprediction for others. Moreover, the models show a phase lag or lead in the arrival peak surge at a given location, depending on the effect of changing the parameter. The highest peak water levels of about $1.5 \mathrm{~m}$ are observed at Naples and Fort Myers, while the lowest peak water levels of about $0.6 \mathrm{~m}$ occurred at Port Manatee and Clearwater beach. The east coast stations have mostly positive surges, although they have low tide times. On the contrary, the west coast stations have negative surges of $-1 \mathrm{~m}$ or more for 18 to $24 \mathrm{~h}$, which is related to the offshore wind pushing water away when the hurricane was approaching the stations. The surge reversed once the hurricane wind came onshore after the eye passed over the stations. This phenomenon has been well documented after the hurricane $[14,15]$, although it was not reported in the advisories. 


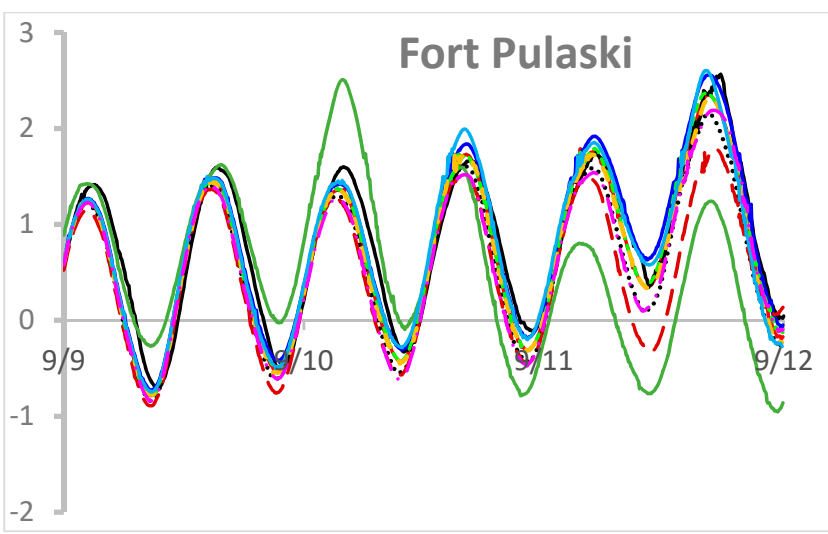

(a)

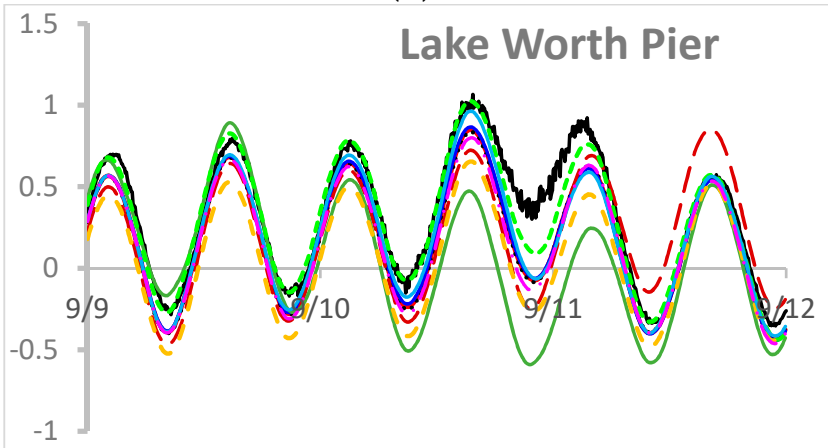

(c)

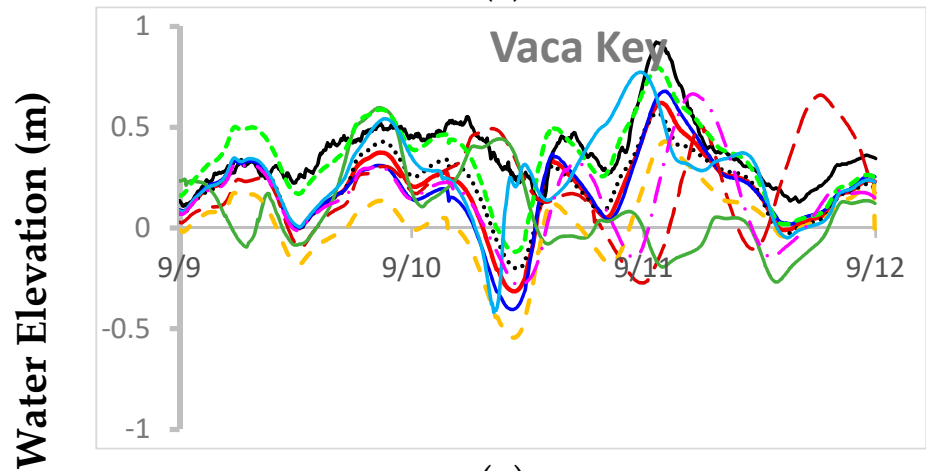

(e)

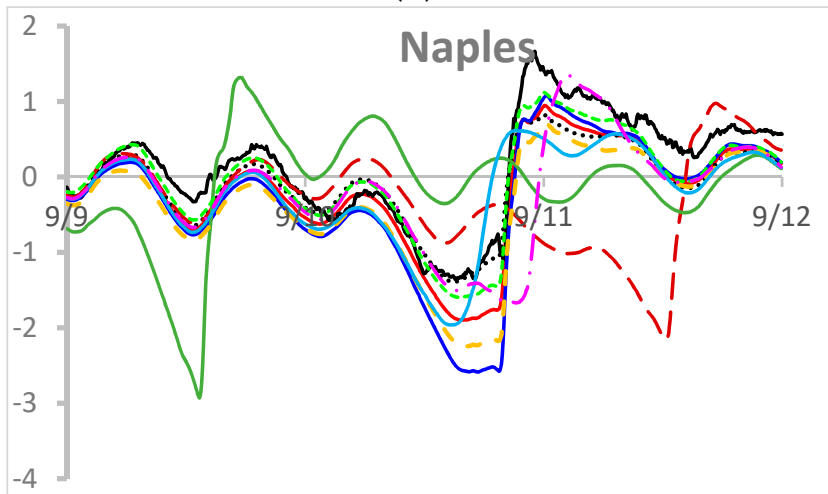

(g)

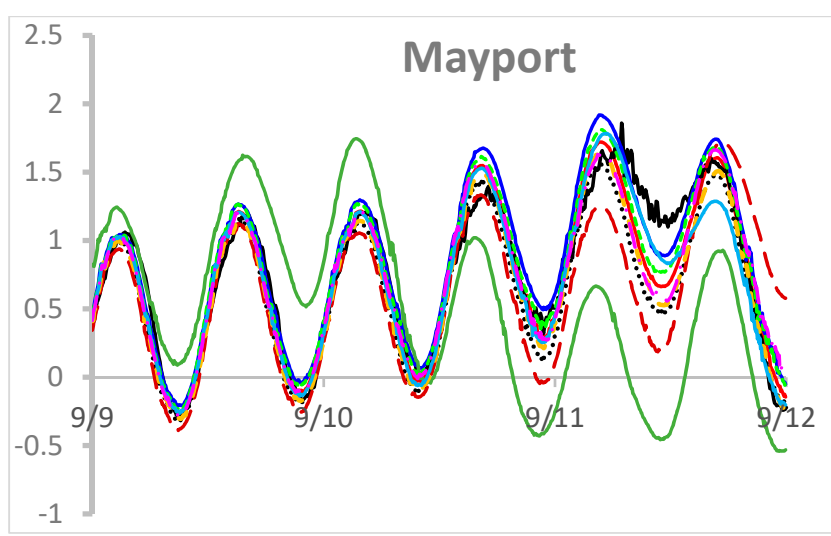

(b)

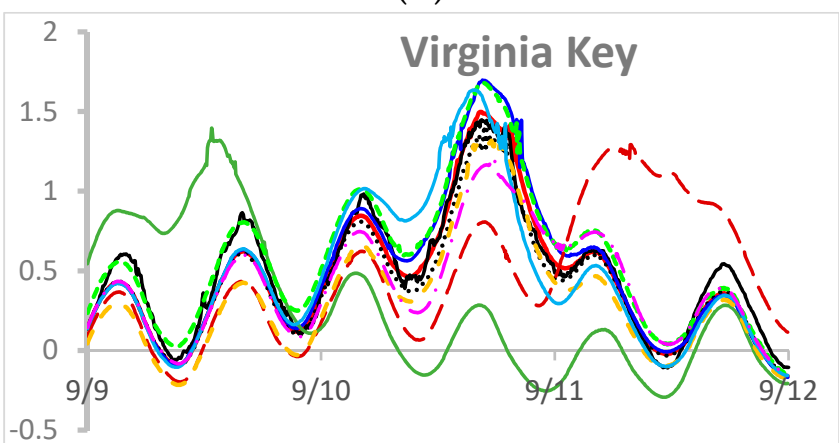

(d)

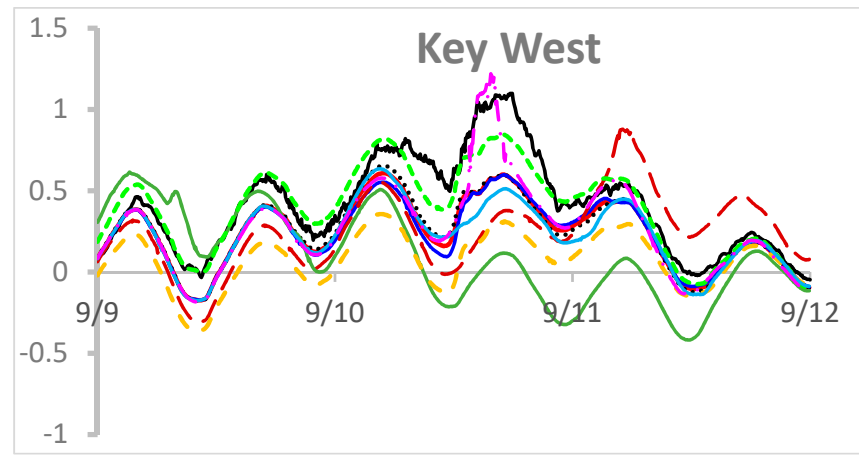

(f)

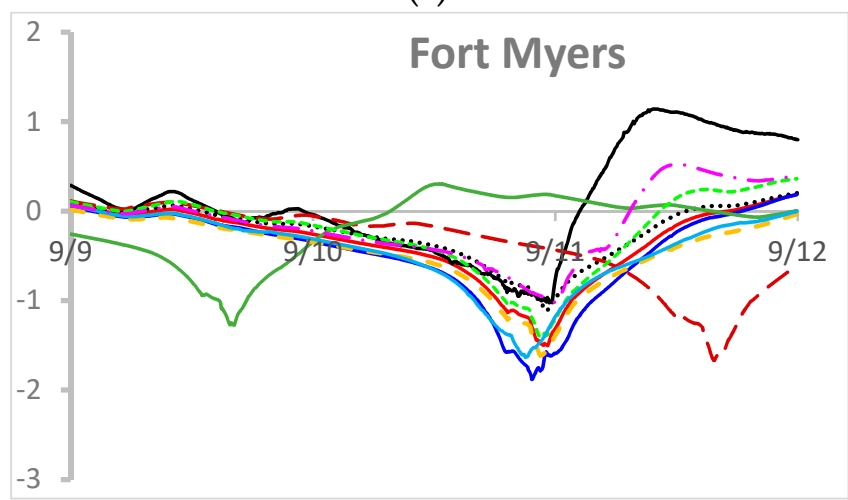

(h)

Figure 6. Cont. 


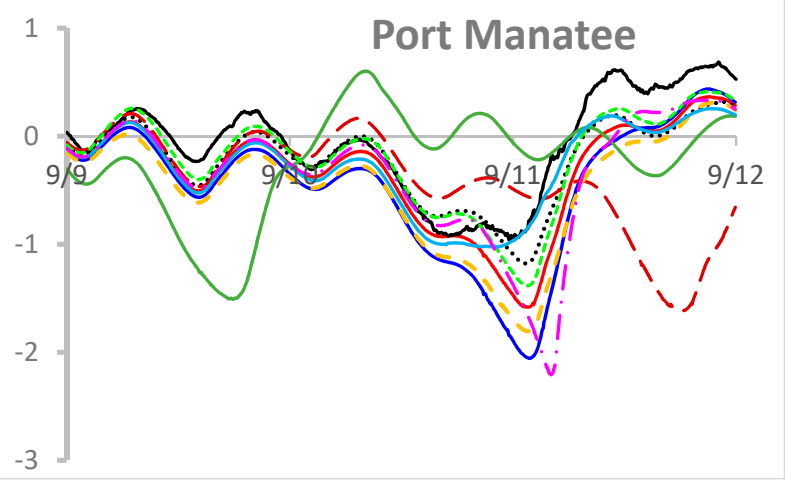

(i)

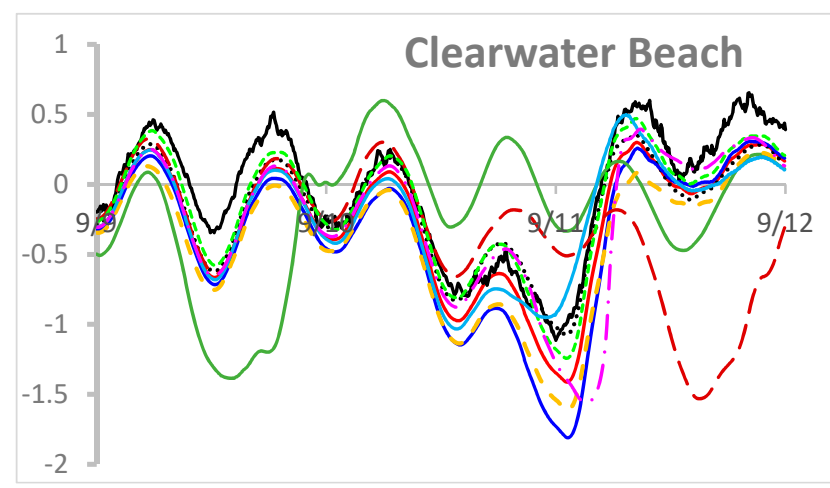

$(\mathbf{j})$

\section{Date and Time}

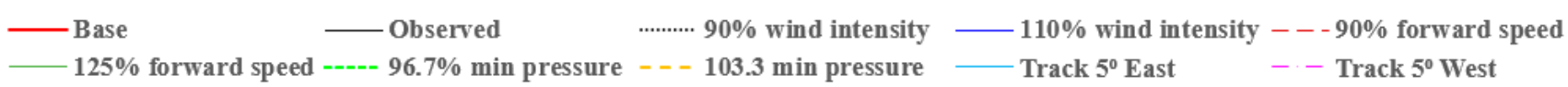

Figure 6. Observed and modeled water elevation time series (date in 2017) for Irma at selected stations using different meteorological forcing cases in Advanced CIRCulation and Simulating Waves Nearshore (ADCIRC + SWAN), (a) Fort Pulaski, (b) Mayport, (c) Lake Worth Pier, (d) Virginia Key, (e) Key West, (f) Vaca Key, (g) Naples, (h) Fort Myers, (i) Port Manatee, and (j) Clearwater Beach.

An identical effect of wind intensity is observed in almost all stations. When wind intensity is increased, water levels are higher than that of the reference (i.e., Case 1) model. The greatest effect of increasing wind intensity occurs at the Virginia Key station (Figure 6d), indicating that stronger winds produce a high inundation in the Miami and Biscayne Bay areas. Peak water levels tend to decrease when wind intensity is decreased. In the Florida Keys, the effect of an increasing wind intensity appears to be higher on the east of the track than on the west side of the track due to the steering counterclockwise winds, as shown in Figure 6e, f for Vaca Key and Key West stations, respectively.

Reducing pressure increases the peak water levels, while increasing pressure decreases the water levels at all selected stations. However, increasing or decreasing pressure produces about the same magnitude of impact on storm surges. The greatest impact of pressure occurs in the southeast coast at Lake Worth Pier and Virginia Key stations and in the Florida Keys at Vaca Key and Key West stations. At these stations, onshore winds combine with a low barometric pressure to generate the highest storm surges. As the center moved northward towards the west coast, changes in barometric pressure had no apparent effect on the Irma storm surge, but wind forcing was more influential. Similar results were obtained by [15].

Changes in the forward speed result in a phase lead or phase lag of peak water levels. When forward speed is increased by $25 \%$, peak surges occur with a phase lead of $30 \mathrm{~h}$, but a decreasing forward speed by $10 \%$ results in a phase lag of $17 \mathrm{~h}$. In a previous study, Musinguzi et al. [7] observed a phase lead of $36 \mathrm{~h}$ when hurricane Rita's forward speed was increased by $25 \%$. At Vaca Key and Key West stations, reducing forward speed has more of an impact on surge than an increasing forward speed, implying that slowing the hurricane gives it more time to inundate the islands, while a fast-moving hurricane quickly passes the islands. At stations in southwest Florida, increased forward speed caused more surge relative to the reference (Case 1) model. This can be explained by the wind directions in Figure 3, which were predominantly southwestward before Irma moved northwards, but later the wind directions became primarily northeastward, pushing more water back overland. In east Florida, at Lake Worth Pier and Virginia Key stations, changes in the forward speed does not indicate significant changes in peak water line timeseries, further confirming that low barometric pressure was a significant contributor to high peak storm surges on the east coast. 
When the track shifted $5^{\circ}$ west of the original track, it increases peak water levels on the west coast. This is demonstrated by higher peak surges at the Key West and Naples stations. When the track is shifted $5^{\circ}$ east, an increase in peak surges occur at stations on the entire Florida east coast, Georgia-Carolinas coastline. NOAA stations at Mayport, Lake Worth Pier and Virginia Key indicate an evident increase in maximum surge. The greatest increase in peak surges of about $0.8 \mathrm{~m}$ occurs at Key West station, when the track in shifted $5^{\circ}$ east.

\subsection{High Water Marks}

High water marks (HWMs) are typically collected from the water marks left on structures, poles and trees after hurricane storm surges recede, and serve as important gauges to assess the worst storm surge which occurred at a given location over the entire duration of the storm. A comparative study of observed and modeled HWMs is a tool to assess model performance with respect to the observed data. However, it should be noted that not all HWM stations may be found to be wet in a typically ADCIR simulation. Hence, some stations may be predicted by the model as dry stations. This situation may be tied to a lack of model mesh resolution, outdated bathymetry, inaccurate input parameters, etc. A total of 47 National Ocean Service observed High-Water Marks (HWMs) are used to evaluate the performance of each modeled water level against the observed HWMs. The observed HWMs and their locations with respect to the coast lines are shown in Figure 1b. Most of the high valued HWMs stations are on the east coast, along the GeorgiaCarolinas coastline and low valued HWMs stations are on the southwest coast of Florida. In Figure 7, the points are color-coded based on the surge (predicted minus observed). White-coded points indicated that HWM was well predicted by the ADCIRC model. These were characterized as those with surge differences within $\pm 0.25 \mathrm{~m}$. Red points indicate dry points. These locations were not wetted by the model. Green-coded points indicate underpredicted HWM locations and yellow-coded points indicate overpredicted HWM.

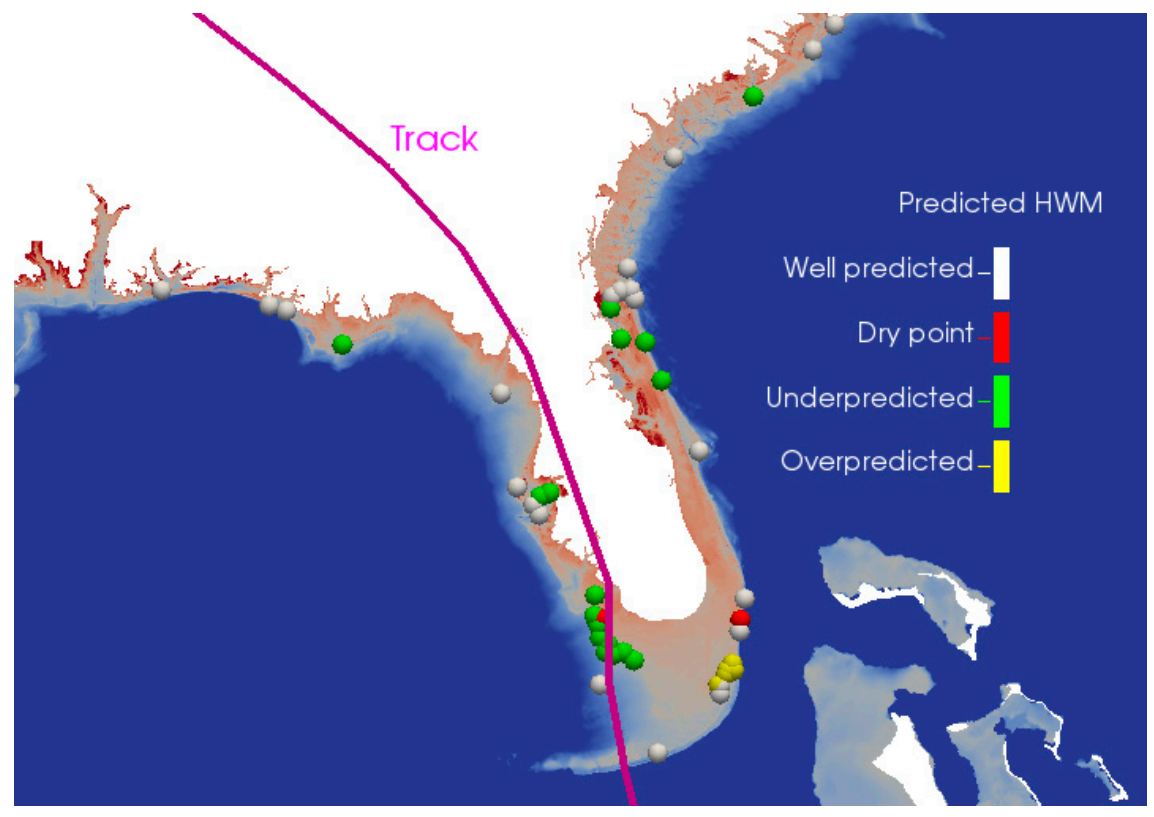

Figure 7. Predicted HWMs at the various USGS locations using OWI meteorological forcing.

In the statistical analysis of HWMs, the number of points wetted by the ADCIRC model vary for all the simulated cases. The high-water mark locations not wetted by the model (dry points) are omitted in the computation of error statistics [2,7]. A comparison between observed and modeled HWMs, the number of wet-dry locations and the error statistics for different cases are presented in Table 3. Figure 8 shows scatter plots for the 
modeled and observed HWMs. The red square points indicate over-prediction by the model, while blue diamond points indicate underprediction by the model. The black line represents the best line of fit. In Table 3, the simulation with OWI meteorological forcing has a Correlation Coefficient $\left(R^{2}\right)$ value of 0.697 , a Mean Normalized Bias $\left(B_{M N}\right)$ value of -0.138 and the Root Mean Square Error $\left(E_{R M S}\right)$ is 0.143 . The $E_{R M S}$ assesses how scattered the data points are, which is largely attributed to the underprediction of HWMs at most of the locations. The $B_{M N}$ assesses how the modeled elevations are on a par with observed data. An overall negative value of Mean Normalized Bias $\left(B_{M N}\right)$ indicates an underprediction of HWMs by the OWI model. Most of the underprediction occurred at the Naples and Fort Myers areas, also shown by water level time series in Figure 6g,h. In a previous study, Hurricane Irma HWMs located in South Florida mangrove zones were under-predicted using the CEST Model [25]. They attributed this underprediction to the proximity of these areas to the domain boundary, resulting in a limited fetch for wind to push water inland. The OWI simulation overpredicted HWMs located around Virginia Key. This is further evidenced by the overprediction of water level timeseries at Virginia Key station as shown in Figure 6d.

Table 3. High Water Mark (HWM) Error Statistics for different cases.

\begin{tabular}{cccccc}
\hline Case & $\boldsymbol{R}^{\mathbf{2}}$ & $\boldsymbol{E}_{\boldsymbol{R} M S}$ & $\boldsymbol{B}_{\boldsymbol{M N}}$ & Dry Points & Wet Points \\
\hline $100 \%$ wind intensity & 0.697 & 0.143 & -0.138 & 2 & 45 \\
\hline $90 \%$ wind intensity & 0.705 & 0.181 & -0.219 & 4 & 43 \\
\hline $110 \%$ wind intensity & 0.703 & 0.139 & -0.032 & 2 & 45 \\
\hline $90 \%$ forward speed & 0.631 & 0.189 & -0.191 & 3 & 44 \\
\hline $125 \%$ forward speed & 0.737 & 0.101 & -0.092 & 2 & 45 \\
\hline Track $5^{\circ}$ West & 0.817 & 0.092 & -0.140 & 3 & 44 \\
\hline Track $5^{\circ}$ East & 0.650 & 0.273 & -0.066 & 6 & 41 \\
\hline 965 min pressure & 0.729 & 0.160 & -0.192 & 6 & 41 \\
\hline 905 min pressure & 0.686 & 0.116 & -0.047 & 2 & 45 \\
\hline
\end{tabular}

As shown in Table 3, when wind intensity is increased to $110 \%$, the $R^{2}$ increases to 0.703 , while the $E_{R M S}$ decreases to 0.139 . As the comparison between Figure 8a,c shows, increasing the wind intensity to $110 \%$ has improved the modeled HWM to be on a par with the observed data, as most HWMs are elevated, as indicated by a lower absolute value of $B_{M N}(0.032)$. When the forward speed is decreased, the model produces the worst statistics by reducing $R^{2}$ to 0.631 , increasing the absolute value of $B_{M N}$ to 0.191 , increasing $E_{R M S}$ to 0.189 , and increasing the number of dry locations to 3 . When the forward speed is increased, $R^{2}$ is higher than the reference model with a smaller error and a lower absolute value of $B_{M N}$. Note that for the higher forward speed case, the HWM may occur a day or two earlier than that of the reference case, as Figure 6 indicates. The highest $R^{2}$ was 0.817 and the smallest $E_{R M S}$ was 0.092 , although a moderate absolute value of $B_{M N}(0.14)$ with 3 dry locations occur when hurricane track is shifted $5^{\circ}$ west. When the track is shifted $5^{\circ}$ east, $R^{2}$ reduces to $0.650, E_{R M S}$ increases to 0.273 , scatter and the number of dry locations increases to 6, but $B_{M N}$ improves overall. Increased pressure gives an $R^{2}$ of 0.729 and an $E_{R M S}$ of 0.160 , although the number of dry locations increases to 6 . When pressure is decreased, $R^{2}$ decreases to 0.686 and $E_{R M S}$ decreases to 0.116 . The best overall HWM performance is obtained when the wind intensity is increased to $110 \%$. 


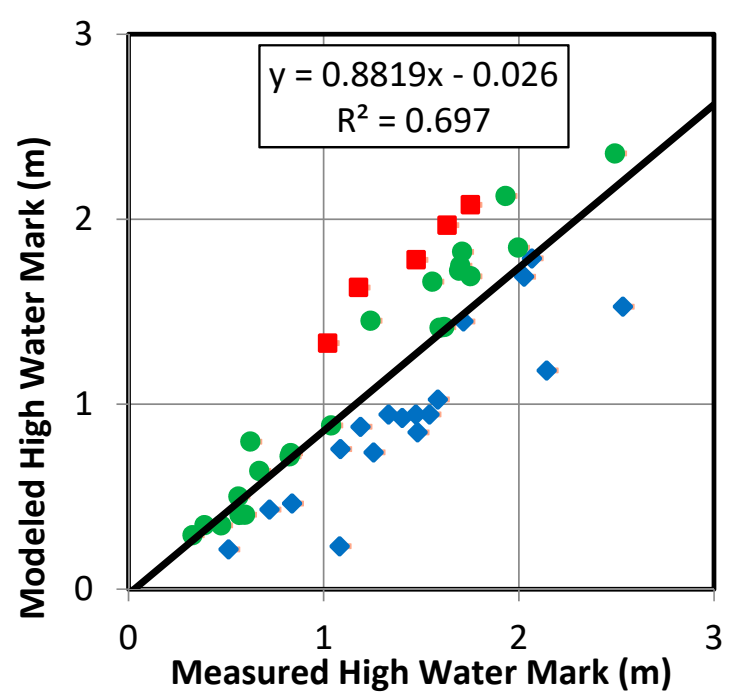

(a)

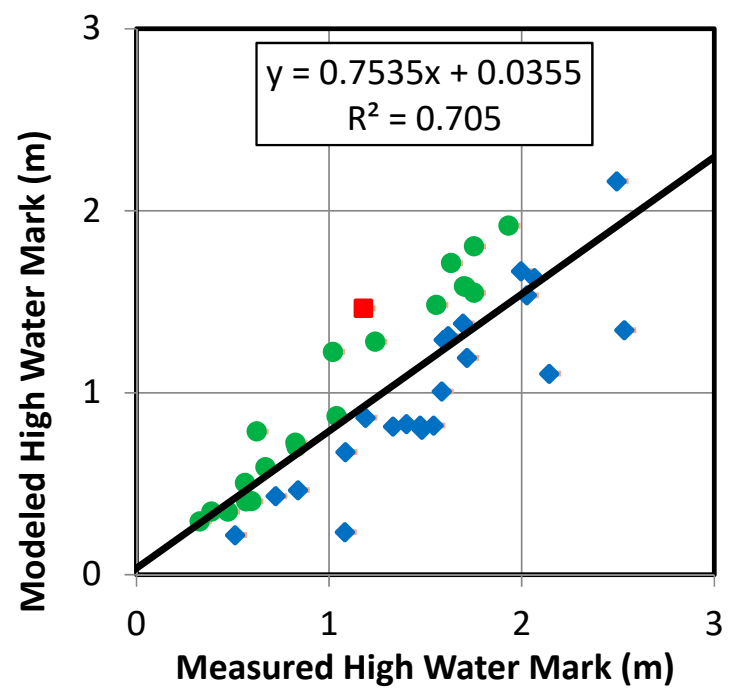

(c)

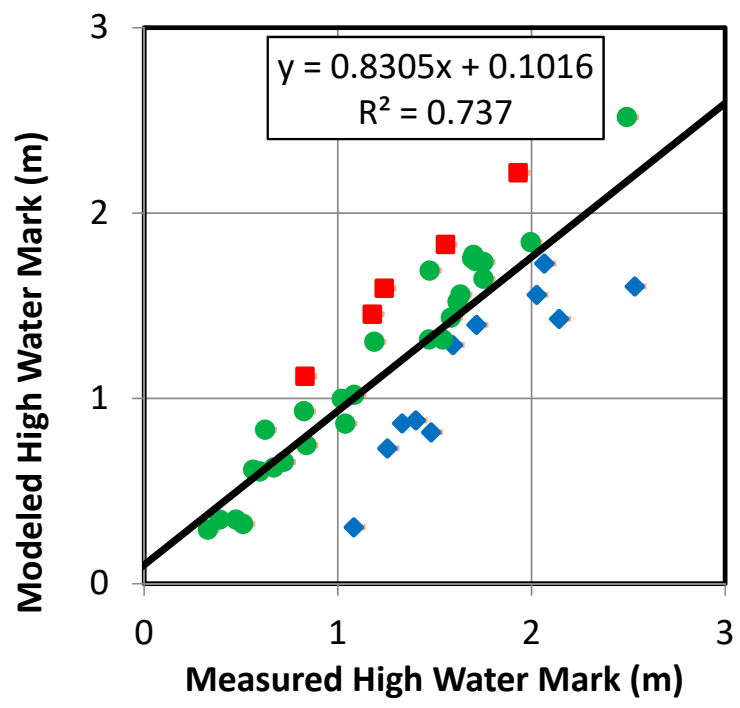

(e)

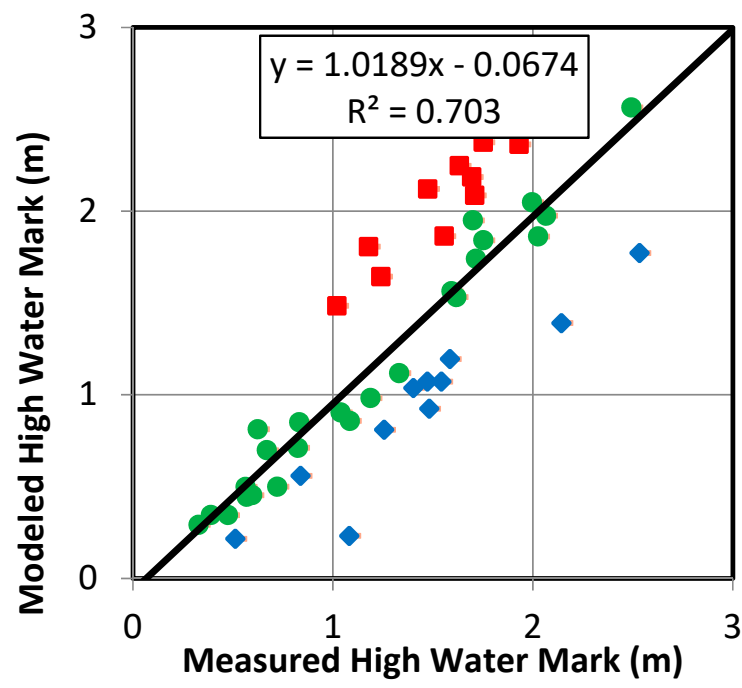

(b)

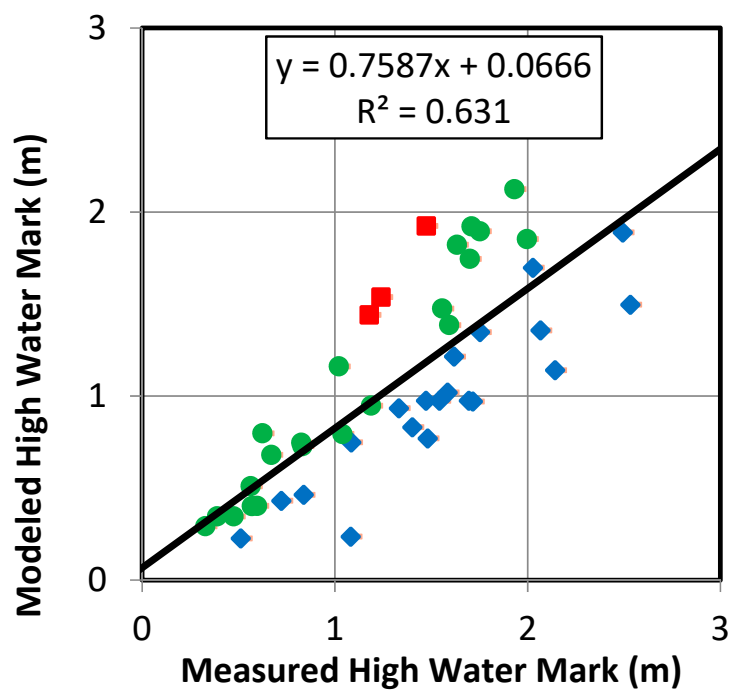

(d)

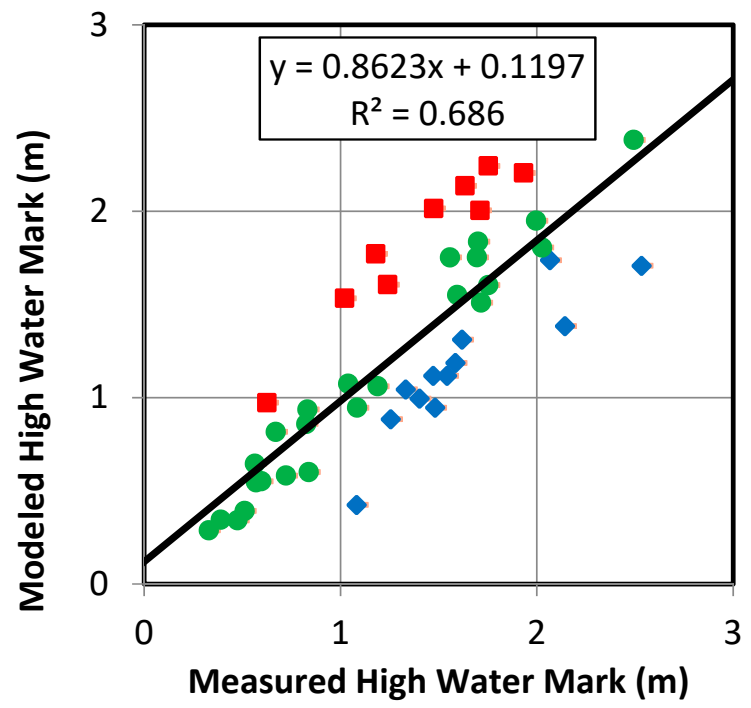

(f)

Figure 8. Cont. 


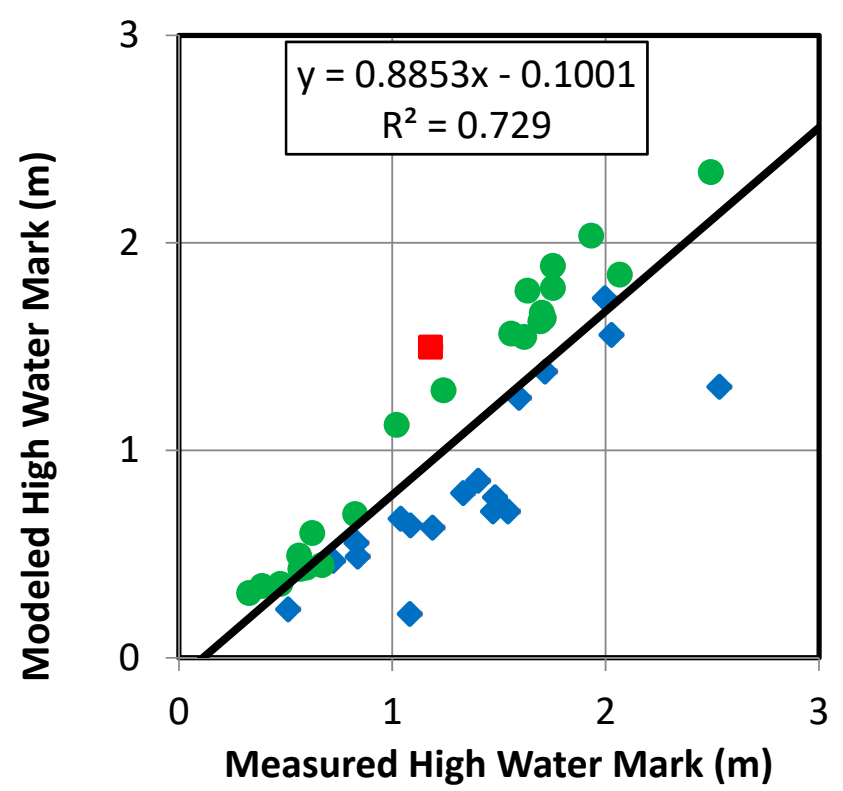

(g)

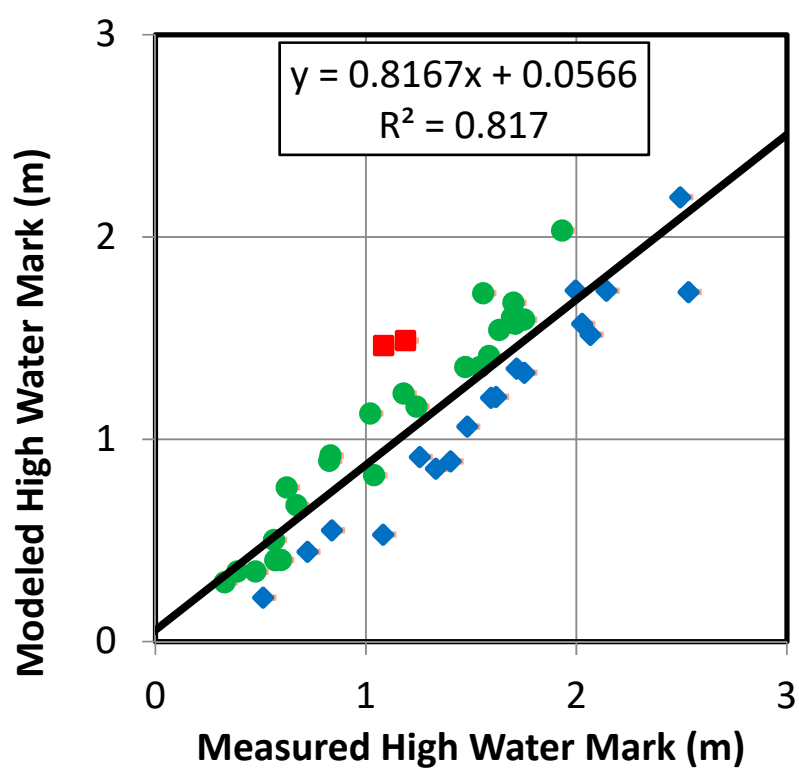

(h)

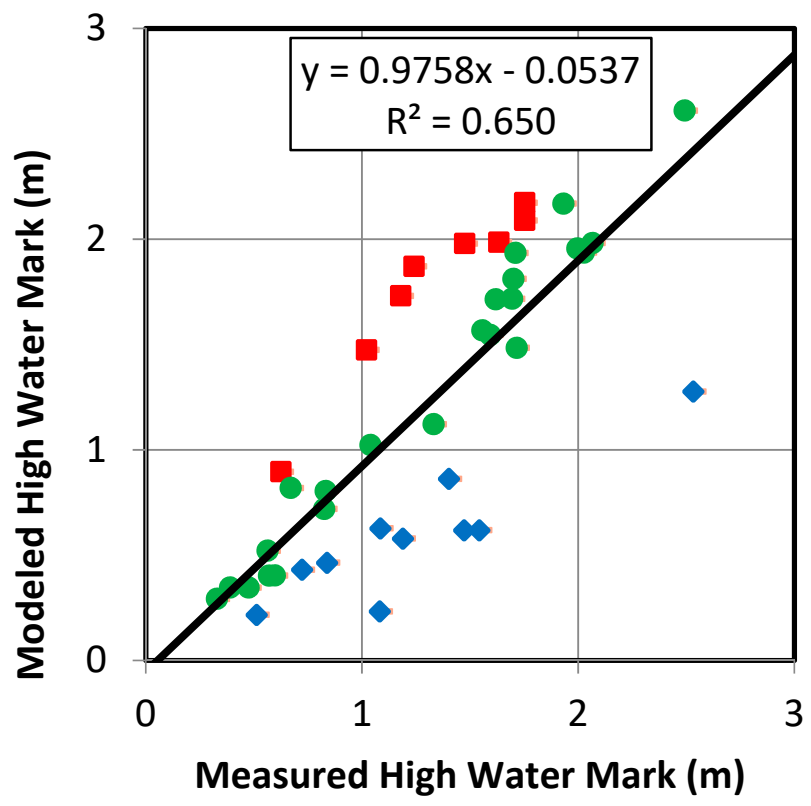

(i)

Figure 8. Comparison between the computed and the measured HWMs at the various USGS locations. (a) Case 1, (b) Case 2, (c) Case 3, (d) Case 4, (e) Case 5, (f) Case 6, (g) Case 7, (h) Case 8, (i) Case 9. The black line represents the best line of fit.

\subsection{Combined Effect of Wind Intensity, Forward Speed and Pressure}

In Figure 9, the combined effect of wind intensity, forward speed and pressure is examined. As presented in Table 1, wind intensity, forward speed and pressure are simultaneously increased and/or decreased. The maximum water level differences between each simulation in Cases 10-15 and the reference simulation are computed using the maximum water elevation at each node. These maximum water elevation differences are used to ascertain the combined effects of wind intensity, forward speed and pressure. 


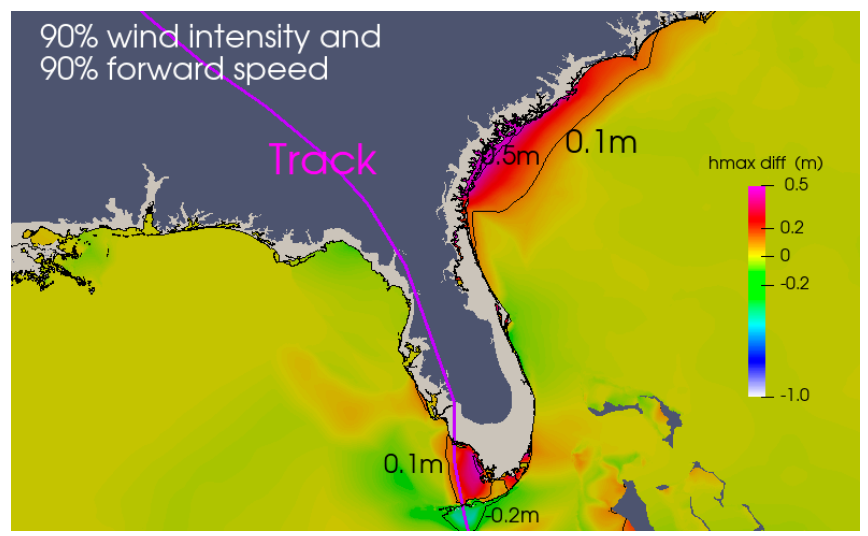

(a)

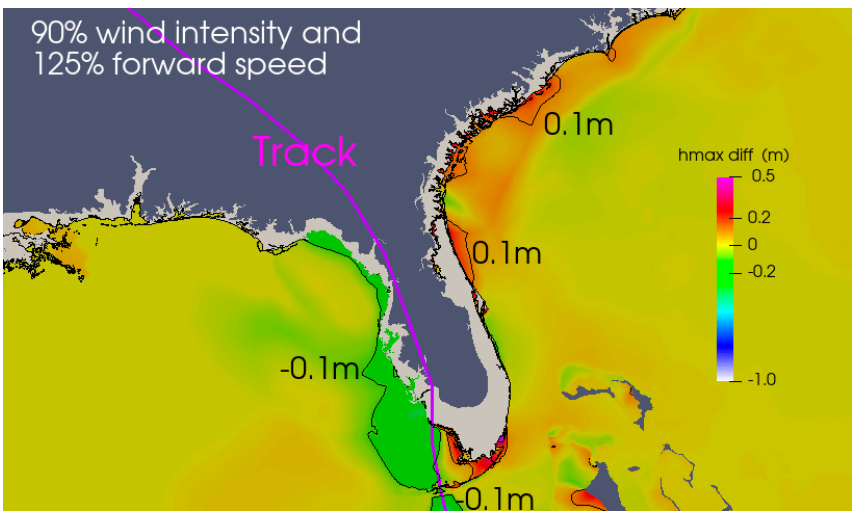

(c)

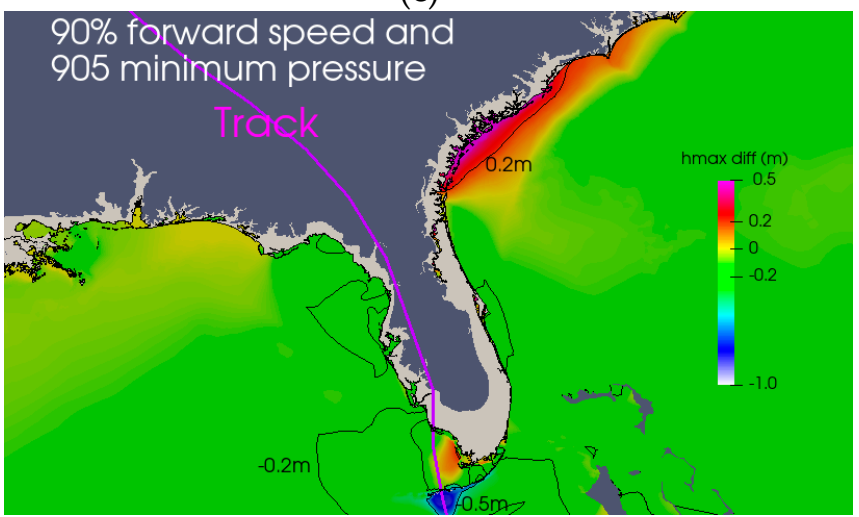

(e)

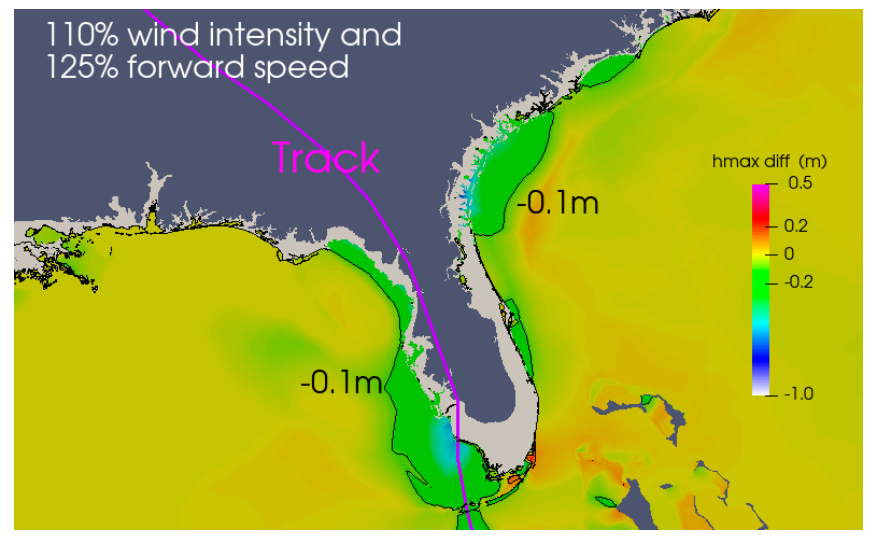

(b)

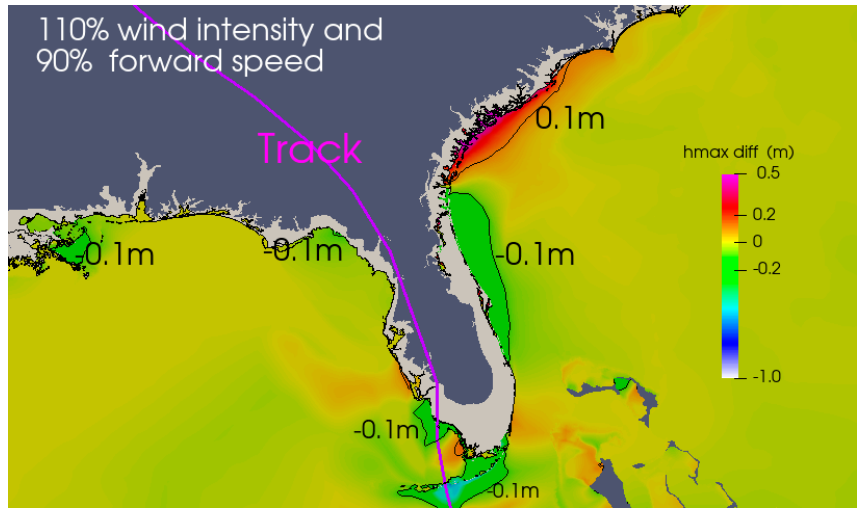

(d)

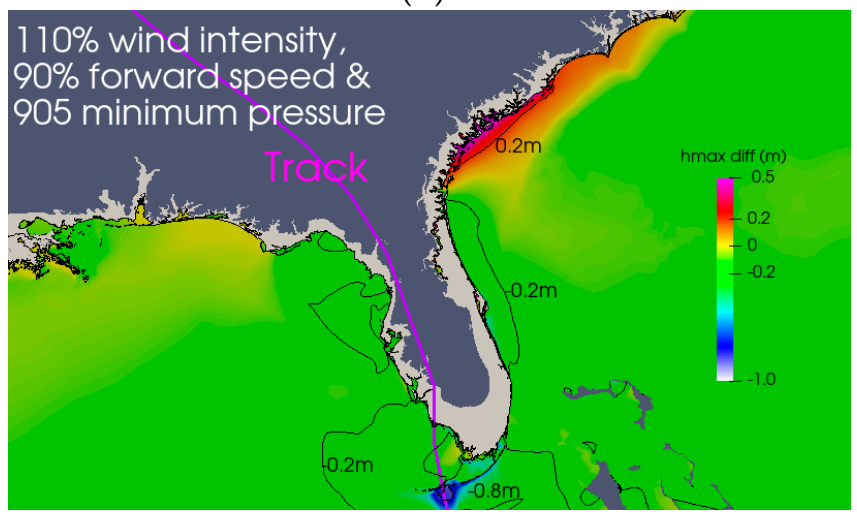

(f)

Figure 9. Departure of maximum water elevations from the base case (i.e., "hmax" of each simulation is subtracted from that of the reference simulation); (a) Case 1-Case 10; (b) Case 1-Case 11; (c) Case 1-Case 12; (d) Case 1-Case 13; (e) Case 1-Case 14; and (f) Case 1-Case 15. Purple lines represent the Irma track.

As shown in Figure 9a, when both wind intensity and forward speed are decreased, the storm surge decreases by about $0.2 \mathrm{~m}$ in southwest Florida, north of Key West, and by about $0.5 \mathrm{~m}$ in the northeast along the recess of the Georgia-Carolinas shoreline. The west coast remains mostly unaffected. However, the peak surges increase by more than $0.2 \mathrm{~m}$ in the south of Florida Keys. On the southwest coast, the decrease in wind intensity weakens the northeastward winds, pushing water up overland, but in Florida Keys, the increase in the surge is because the slow forward speed of the hurricane allows more time to inundate the entire islands. In the recess of the Georgia-Carolinas shoreline, the decrease in surge is because of weaker shore perpendicular (see Figures 3 and 5) winds pushing water overland. When both parameters are increased, as seen in Figure 9b, higher winds 
push more surge north of the keys and the south and west coast of Florida. In the northeast, along the recess of the Georgia-Carolinas coastline, there is a clear increase in surge as well, which is because of the stronger shore perpendicular winds pushing water overland. This combination appears to generate a large surge all around the Florida peninsula, except on the east coast. The effect of the surge on the east coast of Florida is relatively less, as water may easily slide up the coastline.

In Figure 9c, when the wind intensity is decreased and the forward speed is increased, near the southeast of Florida, the surge is decreased and increased on the right and left side of the track, respectively. The peak water levels in the Florida Keys east of landfall decreased due to a weaker but faster wind pushing water to go past the islands. As observed before, decreased wind intensity causes the surge to slightly decrease in the northeast recess of the Georgia-Carolinas coastline. However, the surge on the west coast increases, which can be largely attributed to the increased forward speed. When wind intensity is increased and the forward speed is decreased, as shown in Figure 9d, surges increase throughout the Florida Keys and east Florida. The west coast remains mostly unaffected. In the northeast recess of the Georgia-Carolinas shoreline, a decrease in surge occurs.

The combined effect of decreasing the forward speed and a reduced pressure is analyzed in Figure 9e. It is observed that the surge increase occurs in most parts of the Florida Keys by more than $0.5 \mathrm{~m}$. This increase extends to southeast Florida in the Biscayne Bay and Miami areas. A simultaneous decrease in forward speed and pressure potentially increases the surges in most parts of the west, south and east coasts of Florida. A decrease in surge occurs in the northeast recess of the Georgia-Carolinas coastline.

In Figure 9f, the combined effect of wind intensity, forward speed and pressure is studied by simultaneously increasing wind intensity but decreasing both the forward speed and pressure. This parametric combination produces the greatest storm surge impact in and around Florida, with a more than $0.8 \mathrm{~m}$ increase in surge observed around the Florida Keys. A decrease in surge occurs in the northeast recess of the Georgia-Carolinas coastline. The overall effect is similar, but more intense than the case presented in Figure 9e. The higher wind intensity pushes the water to cause overland flooding.

The ADCIRC + SWAN water level time series for the combined effect of wind intensity and forward speed are compared to the observed water levels at 10 stations, as shown in Figure 10. Note that there is a time lead or lag wherever there is an increased or decreased forward speed, respectively. When both wind intensity and forward speed are decreased, an increase in the water level time series occurs in Florida Keys around the landfall areas. For instance, an increase in surge happens at the Key West station, indicating that a slow forward speed essentially inundates Florida Keys regardless of the wind for both high and low wind intensities. When both parameters are increased, water level time series indicate that the surge increases in southwest Florida as well as in Florida Keys. In the northeast recess of the Georgia-Carolinas coastline, the surge is increased at Pulaski and Mayport stations. However, there is not much change in the surge in the stations located on the east coast (Virginia Key and Lake Worth Pier), indicating the less sensitivity of storm surges to changes in the wind on the southeast coast.

When the wind intensity is reduced and the forward speed is increased, the water level timeseries at Vaca Key and Key West stations in Florida Keys decrease relative to the reference (Case 1) simulation. The surge in the northeast recess of the Georgia-Carolinas coastline decreases, as seen in the timeseries of Fort Pulaski and Mayport stations (see Figure 10a,b, respectively). When the wind intensity is increased and the forward speed is reduced, an increase in surges occurs in the Florida Keys, as shown by the water level time series at Vaca Key and Key West stations, while no difference in peak water levels occur at the Virginia Key and Lake Worth Pier stations. This confirms the findings that a high wind intensity and/or a slow forward speed increases peak surges in the Florida Keys, while wind intensity plays a big factor in the flooding in the northeast recess of the Georgia-Carolinas coastline. 


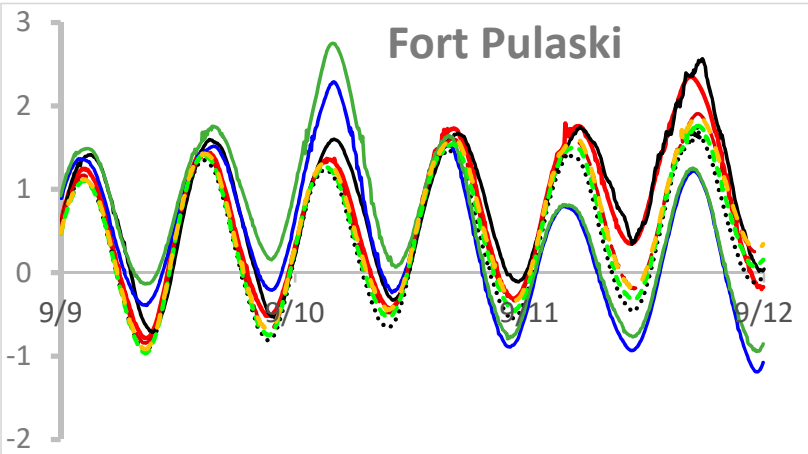

(a)

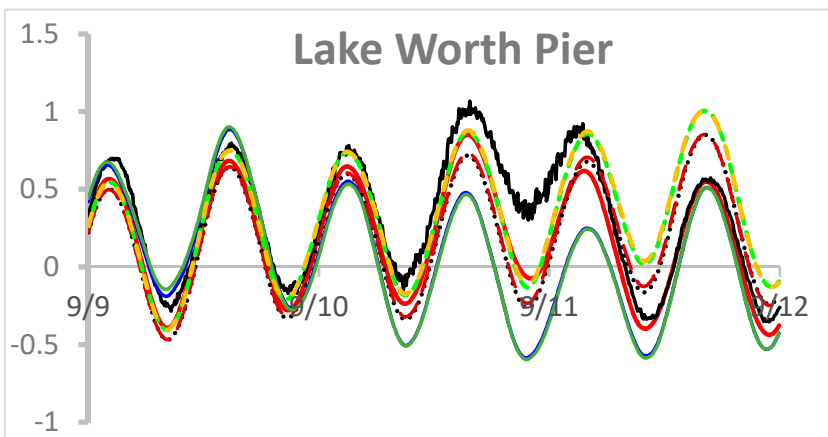

(c)

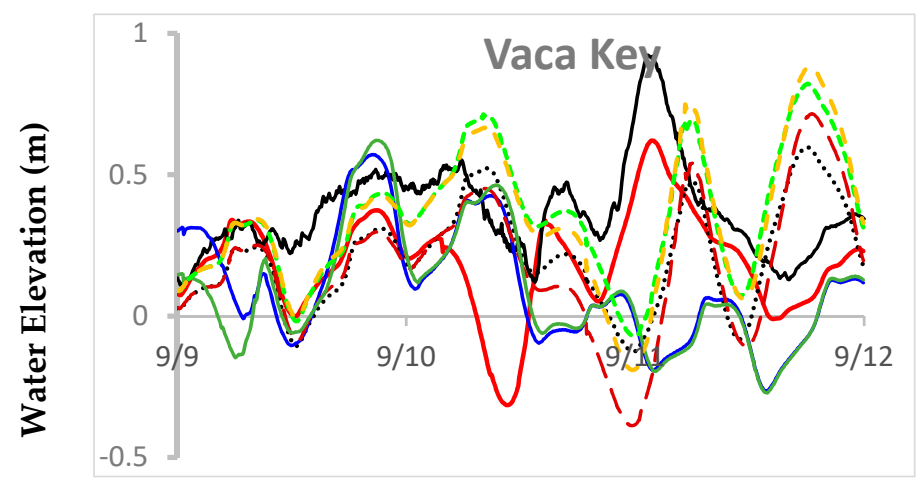

(e)

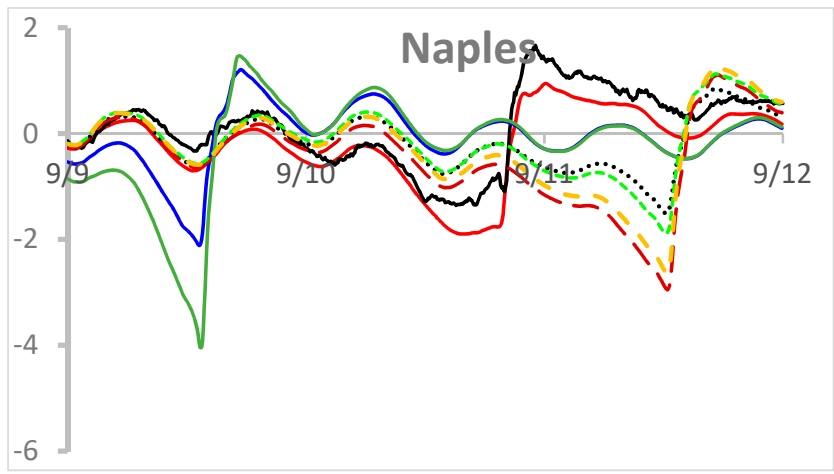

(g)

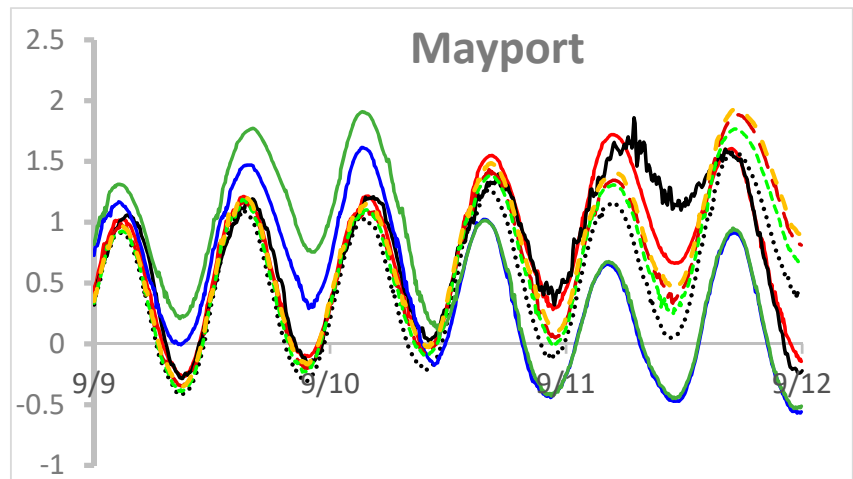

(b)

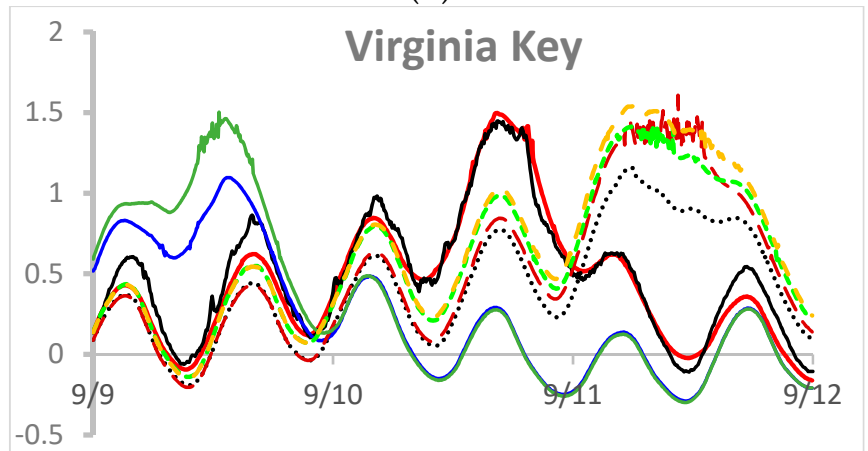

(d)

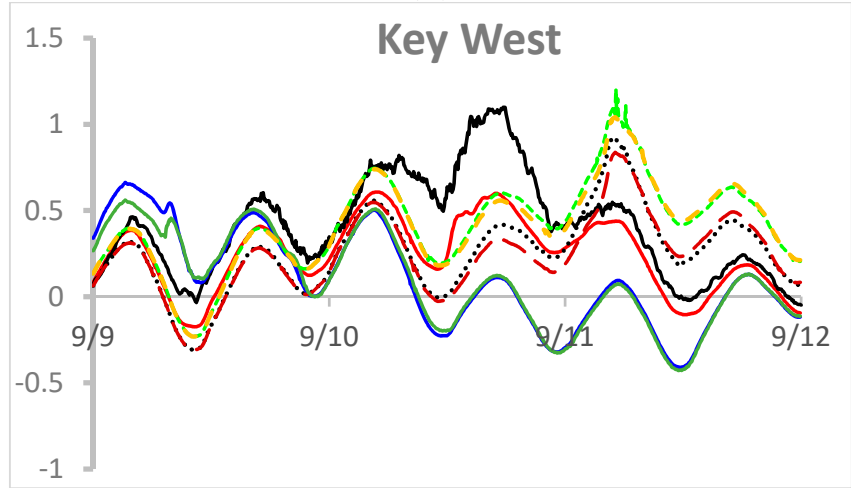

(f)

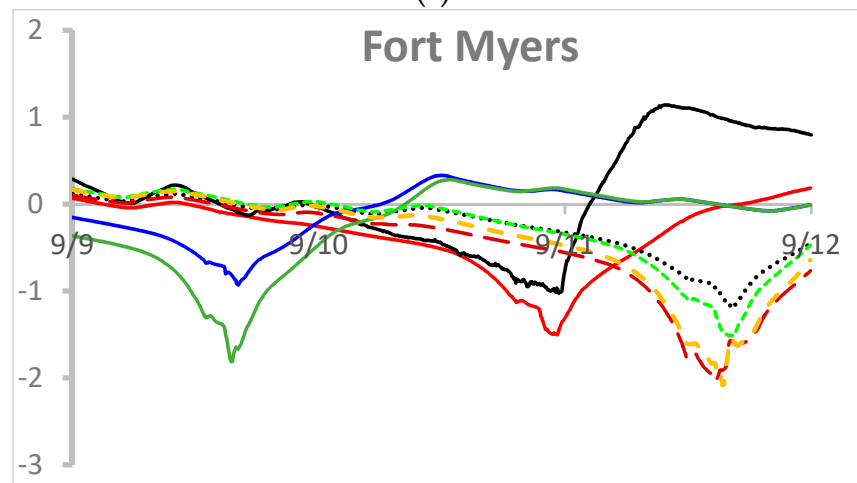

(h)

Figure 10. Cont. 


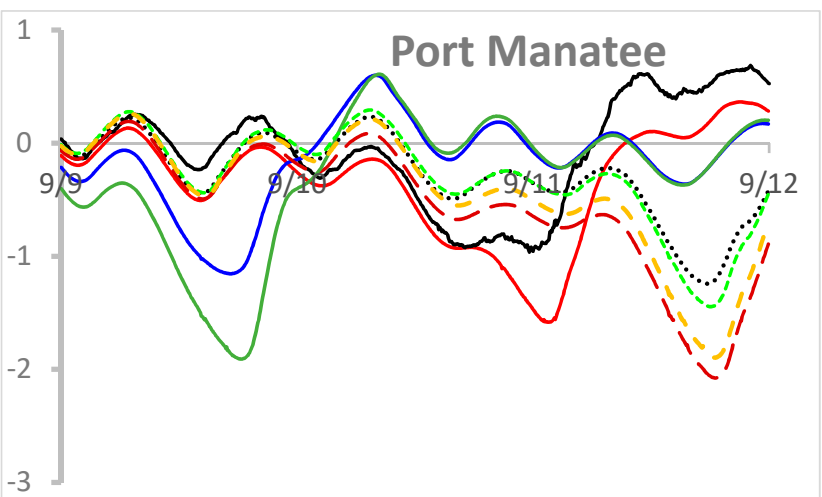

(i)

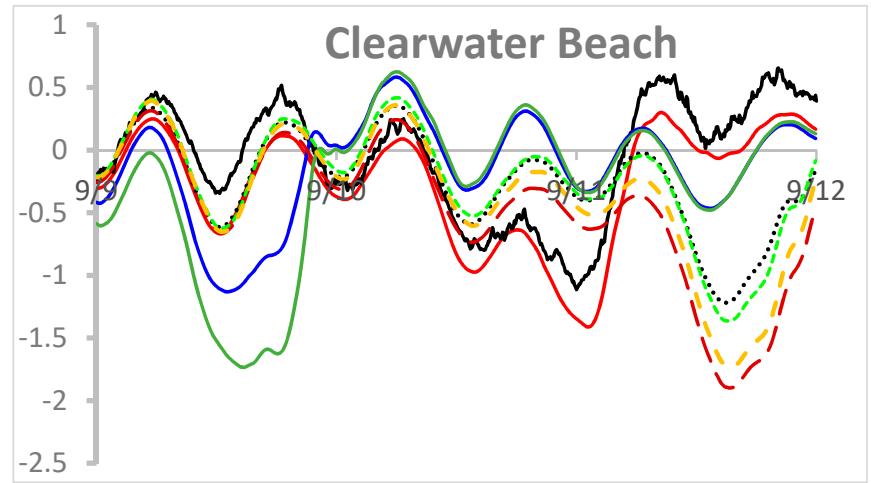

(j)

\section{Date and Time}
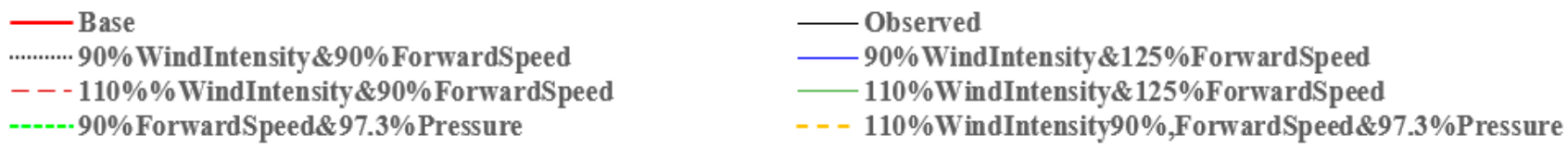

Figure 10. Observed and modeled water elevation time series (date in 2017) for Irma at selected stations using different. meteorological forcing cases in Advanced CIRCulation and Simulating Waves Nearshore (ADCIRC + SWAN), (a) Fort Pulaski, (b) Mayport, (c) Lake Worth Pier, (d) Virginia Key, (e) Key West, (f) Vaca Key, (g) Naples, (h) Fort Myers, (i) Port Manatee, and (j) Clearwater Beach.

The combined effect of a simultaneous increase in wind intensity and a decrease in both the forward speed and pressure is a combination with the greatest effect in increasing the storm surge in the south of Florida. This effect is most critical in the Florida Keys, as seen in water timeseries at the Key West station (Figure 10e). However, this combination causes a decrease in surge in the northeast recess of the Georgia-Carolinas coastline, especially at Fort Pulaski station (Figure 10a).

All west coast stations experience negative surges, as discussed before. Positive surges recede once the hurricane eye passes over the stations.

\section{Conclusions}

This study conducts numerical experiments using SWAN + ADCIRC to extensively study storm surge impacts caused by Hurricane Irma around the Florida peninsula under varying parametric conditions. The results show that on the west coast, peak surges are markedly different from the east coast. The onshore winds perpendicular to the coastline increase the surge, and offshore winds perpendicular to the shoreline have an opposite effect. The west coast initially has a negative surge due to counter-rotating offshore wind, but the surge reverses after the hurricane eye passes over the location and the wind turns onshore. The east coast surge is largely positive, except for the periods of low tides. The surge on the east coast of south Florida is not significant, as water can slide north along the coastline. The results demonstrate the importance of considering changes in the coastline orientation in storm surge predictions.

When wind intensity is increased by $10 \%$, about a $0.2 \mathrm{~m}$ increase in peak surges occurs around the landfall areas of south Florida, as well as along the Georgia-Carolinas recessed coastline. Considering the moderate coefficient of determination and scatter, the lowest absolute value of normalized mean bias and the lowest number of dry locations, the best HWM performance is obtained when the wind intensity is increased by $10 \%$. The opposite happens when the intensity is reduced by $10 \%$. A decrease in forward speed by $10 \%$ increases the surge on the south side of Florida Keys by more than $0.4 \mathrm{~m}$, but causes a decrease in surge by the same amount on the north side of Florida Keys and in the recess of Georgia-Carolinas. An increase in forward speed by $10 \%$ produces an increase in surge in the Florida Keys and in southwest Florida of about $0.2 \mathrm{~m}$, and slightly increases the surge 
in the recess of Georgia-Carolinas. The southwest Florida peninsula experiences a higher surge due to a fast-moving storm, while the surge increasing in the Florida Keys is lower for a faster moving storm than for a slower moving storm. The surge level increases or decreases by $0.2 \mathrm{~m}$ for a 30 millibar incremental pressure drop or a rise respectively in the present study. The effect of pressure change on the surge is clearly spread from the track to the open ocean.

Shifting the track $5^{\circ}$ westwards increases the peak surge by more than $0.2 \mathrm{~m}$ on the west coast of Florida, but a 0.2 m lesser surge at the intersection of Florida Keys and continental Florida, as well as in the Georgia-Carolinas recess. This case produces the highest coefficient of determination and the lowest scatter, but a moderate absolute value of normalized mean bias (i.e., somewhat underprediction by model) in the HWM comparison. Shifting the track $5^{\circ}$ eastwards, the track stays on continental Florida for the most part, which minimizes the surge effects overall. The east coast and the Georgia-Carolinas recess have slightly higher surges. Increasing wind intensity and forward speed at the same time contributes to the largest surge effects around the Florida peninsula and the Georgia-Carolinas coastline. Simultaneously increasing wind intensity but decreasing both forward speed and pressure produces the highest surge around the Florida peninsula. It also produces a decreased surge in the recess of the Georgia-Carolinas coastline.

Author Contributions: A.M. performed all runs, post-processed the results, and analyzed the results; M.S. performed some runs and post-processed the results; M.K.A. designed the study, evaluated the results, and provided critical reviews; J.G.F. trained students in the ADCIRC model and provided technical expertise. All authors have read and agreed to the published version of the manuscript.

Funding: This research was funded by National Science Foundation-Excellence in Research, grant number 2000283. The APC is funded by the same grant.

Institutional Review Board Statement: Not applicable.

Informed Consent Statement: Not applicable.

Data Availability Statement: Exclude. (Data sets are huge to be able to share publicly. Authors can share data with researchers privately, if contacted.)

Acknowledgments: Authors are grateful to the University of North Carolina's Renaissance Computing Center for access to their high-performance computing platform.

Conflicts of Interest: The authors declare sole responsibility of the research results.

\section{References}

1. National Hurricane Center. Introduction to Storm Surge. Available online: https://www.nhc.noaa.gov/surge/surge_intro.pdf (accessed on 1 June 2021).

2. Kerr, P.C.; Martyr, R.C.; Donahue, A.; Hope, M.E.; Westerink, J.J.; Luettich, R.A., Jr.; Kennedy, A.; Dietrich, J.; Dawson, C. U.S. IOOS coastal and ocean modeling testbed: Evaluation of tide, wave, and hurricane surge response sensitivities to mesh resolution and friction in the Gulf of Mexico. J. Geophys. Res. Oceans 2013, 118, 4633-4661. [CrossRef]

3. Akbar, M.K.; Kanjanda, S.; Musinguzi, A. Effect of bottom friction, wind drag coefficient, and meteorological forcing in hindcast of Hurricane Rita storm surge using SWAN + ADCIRC model. J. Mar. Sci. Eng. 2017, 5, 38. [CrossRef]

4. Simpson, R.H.; Saffir, H. The hurricane disaster potential scale. Weather 1974, 27, 169. [CrossRef]

5. NOAA NHC. Minor Modification to Saffir-Simpson Hurricane Wind Scale for the 2012 Hurricane Season. 2012. Available online: https:/ / www.nhc.noaa.gov/pdf/sshws_2012rev.pdf (accessed on 28 May 2021).

6. Rego, J.L.; Li, C. On the importance of the forward speed of hurricanes in storm surge forecasting: A numerical study. Geophys. Res. Lett. 2009, 36, 07609. [CrossRef]

7. Musinguzi, A.; Akbar, M.K. Effect of Varying Wind Intensity, Forward Speed, and Surface Pressure on Storm Surges of Hurricane Rita. J. Mar. Sci. Eng. 2021, 9, 128. [CrossRef]

8. Thomas, A.; Dietrich, J.C.; Asher, T.; Bell, M.; Blanton, B.; Copeland, J.; Cox, A.; Dawson, C.; Fleming, J.; Luettich, R. Influence of storm timing and forward speed on tides and storm surge during Hurricane Matthew. Ocean. Model. 2019, 137, 1-19. [CrossRef]

9. National Oceanic and Atmospheric Administration (NOAA). Hurricane Basics. May 1999. Available online: http://www. disastersrus.org/MyDisasters/NOAA/hurricanebook.pdf (accessed on 1 June 2021).

10. Sebastian, A.; Proft, J.; Dietrich, J.C.; Du, W.; Bedient, P.B.; Dawson, C.N. Characterizing hurricane storm surge behavior in Galveston Bay using the SWAN+ ADCIRC model. Coast. Eng. 2014, 88, 171-181. [CrossRef] 
11. Irish, J.L.; Resio, D.T.; Ratcliff, J.J. The Influence of Storm Size on Hurricane Surge. J. Phys. Oceanogr. 2008, 38, 2003-2013. [CrossRef]

12. Flather, R.A. Storm Surges. In Encyclopedia of Ocean Sciences; Steele, J., Thorpe, S., Turekian, K., Eds.; Academic: San Diego, CA, USA, 2001; pp. 2882-2892.

13. Joyce, B.R.; Gonzalez-Lopez, J.; Van Der Westhuysen, A.J.; Yang, D.; Pringle, W.J.; Westerink, J.J.; Cox, A.T. U.S. IOOS Coastal and Ocean Modeling Testbed: Hurricane-Induced Winds, Waves, and Surge for Deep Ocean, Reef-Fringed Islands in the Caribbean. J. Geophys. Res. Oceans 2019, 124, 2876-2907. [CrossRef]

14. So, S.; Juarez, B.; Valle-Levinson, A.; Gillin, M.E. Storm surge from Hurricane Irma along the Florida Peninsula. Estuar. Coast. Shelf Sci. 2019, 229, 106402. [CrossRef]

15. Cangialosi, J.P.; Latto, A.S.; Berg, R. National Hurricane Center Tropical Cyclone Report: Hurricane Irma; National Oceanic and Atmospheric Administration and National Hurricane Center: Miami, FL, USA, 2018; Report no. AL112017.

16. Riverside Technology, Inc; AECOM. Mesh Development, Tidal Validation, and Hindcast Skill Assessment of an ADCIRC Model for the Hurricane Storm Surge Operational Forecast System on the US Gulf-Atlantic Coast. 2015. Available online: https:/ / cdr.lib.unc.edu/concern/parent/8336h638c/file_sets/44558j54m (accessed on 1 September 2021). [CrossRef]

17. Westerink, J.J.; Luettich, R.A.; Blain, C.A.; Scheffner, N.W. An Advanced Three-Dimensional Circulation Model. for Shelves, Coasts and Estuaries; Report 2: Users' Manual for ADCIRC-2DDI; Department of the Army, USACE: Washington, DC, USA, 1992.

18. Kolar, R.L.; Gray, W.G.; Westerink, J.J.; Luettich, R.A. Shallow water modeling in spherical coordinates: Equation formulation, numerical implementation, and application. J. Hydraul. Res. 1994, 32, 3-24. [CrossRef]

19. Musinguzi, A.; Akbar, M.K.; Fleming, J.G.; Hargrove, S.K. Understanding Hurricane Storm Surge Generation and Propagation Using a Forecasting Model, Forecast Advisories and Best Track in a Wind Model, and Observed Data-Case Study Hurricane Rita. J. Mar. Sci. Eng. 2019, 7, 77. [CrossRef]

20. SWAN-Scientific and Technical Documentation Version 40.91AB. Delft University of Technology, Environmental Fluid Mechanics Section. Available online: http:/ / www.swan.tudelft.nl (accessed on 1 June 2021).

21. Luettich, R.A., Jr.; Westerink, J.J. Implementation of the Wave Radiation Stress Gradient as a Forcing for the ADCIRC Hydrodynamic Model: Upgrades and Documentation for ADCIRC Version 34.12; Contractors Report; Department of the Army, US Army Corps of Engineers, Waterways Experiment Station: Vicksburg, MS, USA, 1999; p. 9.

22. Cox, A.T.; Greenwood, J.A.; Cardone, V.J.; Swail, V.R. An interactive objective kinematic analysis system. In Proceedings of the Fourth International Workshop on Wave Hindcasting and Forecasting, Banff, Alberta, 16-20 October 1995; pp. 109-118.

23. Cardone, V.J.; Cox, A.T. Tropical cyclone wind field forcing for surge models: Critical issues and sensitivities. Nat. Hazards 2009, 51, 29-47. [CrossRef]

24. Dietrich, C. How to Hot-Start SWAN+ADCIRC. Coastal \& Computational Hydraulics Team. 15 February 2010. Available online: https:/ / ccht.ccee.ncsu.edu/how-to-hot-start-swanadcirc/ (accessed on 1 September 2021).

25. Li, Y.; Chen, Q.; Kelly, D.; Zhang, K. Hurricane Irma simulation at South Florida using the parallel CEST Model. Front. Clim. 2021, 3, 79. [CrossRef] 